\title{
After-sales Service Competition in a Supply Chain: Does Uncertainty Affect the Conflict between Profit Maximization and Customer Satisfaction?
}

\author{
Hisashi Kurata ${ }^{1}$ \\ Faculty of Engineering, Information and Systems, the University of Tsukuba \\ Seong-Hyun $\mathrm{Nam}^{2}$ \\ College of Business and Public Administration, University of North Dakota
}

\section{Key words}

After-sales service, Uncertainty, Supply chain management, Game theory, Marketing-operations interface.

\footnotetext{
${ }^{1}$ Corresponding author:

Faculty of Engineering, Information and Systems, the University of Tsukuba

3F1227, Tenno-dai 1-1-1, Tsukuba city, Ibaraki 305-8573, Japan

Tel: $+81-(29)-853-5025$

Fax: +81-(29)-853-5070

Email: kurata@sk.tsukuba.ac.jp

${ }^{2}$ Email: SNam@business.und.edu
} 


\title{
After-sales Service Competition in a Supply Chain: Does Uncertainty Affect the Conflict between Profit Maximization and Customer Satisfaction?
}

\begin{abstract}
After-sales services are a key strategic tool in the durable consumer product market. They allow a manufacturer and a retailer to capture more sales and profit. Less obvious, however, is how the uncertainty of the customer's needs for after-sales services influences after-sales service decisions. As an extension of Kurata and Nam's (2010) work, in this paper we explore the effect of uncertainty on after-sales service decisions by comparing several information structures in a two-stage supply chain. The model presented in this paper demonstrates that uncertainty may temporally alleviate the discrepancy between customers' optimal service level and a firm's service decisions based on maximizing profits (referred to here as accidental outperformance). However, ultimately, uncertainty will never improve supply chain performance. We determine probabilities that such accidental outperformance may mislead the firm into making erroneous after-sales service decisions due to misunderstandings regarding uncertainty. In addition, our analysis shows that a firm's effort to provide efficient service operations will increase the chance of accidental outperformance. Based on the analytical results, we also provide several practical insights for business.
\end{abstract}




\section{Introduction}

After-sales service is a strategic tool in the durable consumer product market used to gain more sales, revenue, and profit (e.g., Cohen et al., 2006; Cohen and Kunreuther, 2007). Research on after-sales service covers maintenance and replacement (e.g., Bensoussan and Sethi, 2007), repair services (Amini et al., 2005), spare parts supply (e.g., Thonemann et al., 2002), warranties (e.g., Chukova et al. 2004; Balachandran and Radhakrishnan, 2005; Chu and Chintagunta, 2009), service guarantees (e.g., Hart, 1988; Baker and Collier 2005), customer relationships (e.g., Gupta and Lehmann, 2007), and competition between new and remanufactured products (Wu, 2012) among other things. Another critical issue in supply chain management is the ability to cope with uncertainty in business environments. Uncertainty makes supply chain management difficult, and managing uncertainty is among the most critical supply chain challenges (Simchi-Levi, et al., 2008). In marketing, understanding the target market's needs and wants is a major concern, as often even customers are unaware of their real needs.

Kurata and Nam (2010) studied after-sales service competition, considering profit maximization and customer satisfaction while using the deterministic model in which firms are assumed to understand customers' needs perfectly. However, this assumption has a limitation. In reality, customers' real preferences for services are unknown to businesses. Firms often estimate customers' real needs by conducting market research. Based on the estimations, the firm makes managerial decisions, including those aimed at ensuring the most profitable after-sales service plan. In fact, marketing researchers claim that understanding what the target segment prefers the most is important (Aaker et al., 1998). It is natural that information about customers' preferences is asymmetric between a manufacturer and a retailer; in general, a retailer is considered more knowledgeable about customers than a manufacturer is. Consequently, an asymmetric information structure affects the after-sales service competition in supply chains.

In this paper, as an extension of Kurata and Nam's (2010) work, we discuss whether an equilibrium after-sales service level chosen based on profit maximization is consistent with an optimal after-sales level that would satisfy customers the most. This discussion assumes that the customers' needs are unknown to the firms and that there are two customer segments: the customers who need only base after-sales services offered by manufacturers (hereafter Segment 0 ) and customers who pay additional fees to buy optional after-sales service plans offered by retailers in addition to the manufacturers' base after-sales services (hereafter Segment 1). Figure 1 illustrates the supply chain setting of our research.

\section{(Insert Figure 1 around here)}

The length of the warranty support is an important component of after-sales service. In academic research, warranty length is a common research theme (e.g., Chien 2005, 2012; Jack and Murthy 2006; Lin et al., 2009; Chen, et al., 2010; Wu and Longhurst, 2011; Bouguerra, et al., 2012). Also, research on warranty often sets up two types of warranty, base warranty and extended warranty (e.g., Wu and Longhurst 2011; Bouguerra, et al., 2012), as we assume two types of after-sales service plans, base and optional services. However, in this paper, the meaning of after-sales service is not limited to warranty support, as including all types of service available after the purchase of a product (a free warranty, a telephone or e-mail helpdesk, training sessions, and tutorial materials) is important.

In this paper, we concentrate on two questions regarding the effect of uncertainty on firms' after-sales service decisions. The first asks how the structure of information knowledge 
between a manufacturer and a retailer influences after-sales service decisions under uncertainty. Note that information asymmetry among individual parties in a supply chain is one of the critical aspects that distinguish multi-firm supply chains from traditional centralized inventory systems (Corbett 2001). Corbett et al. (2004) researched the role of information asymmetry in supply chain contracts. Lau and Lau (2005) presented the superiority of a stochastic-and-asymmetric information approach over a deterministic-and-symmetric information approach in supply chain modeling. Özer and Wei (2006) examined the effect of the degree of forecast information asymmetry on coordination between a supplier and a manufacturer. To examine the effect of asymmetric information on customer preference, we compare five different information situations between a retailer and a manufacturer. The second question asks when and how uncertainty will mislead a firm regarding the appropriate level of after-sales service to customers. Uncertainty definitely influences service planning. For example, White (2013) examines how mis-esitmation of production functions affect resource planning of services. Using a deterministic model, Kurata and Nam (2010) demonstrated that an equilibrium after-sales service level that maximizes a firm's profit tends be smaller than the optimal after-sales service level for customers. However, we contend that if uncertainty is included, estimation errors in customer needs for after-sales service will make the equilibrium service level closer to the optimal customer level. Hereafter, this type of accidental improvement in a firm's after-sales service performance is referred to as accidental outperformance. Accidental outperformance is not a real improvement in after-sales service but a lucky mistake due to uncertainty, and may lead to a firm overlooking its incorrect service decisions.

The remainder of this paper is organized as follows: in Section 2, we explain our models, particularly the modeling of uncertainty. In Section 3, we present how information is structured between a manufacturer and a retailer affects after-sales service decisions. In Section 4, we examine how likely it is uncertainty will mislead a firm to accidental outperformance or a wrong after-sales service decision due to uncertainty. In Section 5, we give numerical examples and propose managerial insights derived from the analytical results. Finally, in Section 6, we present our conclusions.

\section{Models}

This paper, as an extension of Kurata and Nam's (2010) paper, developed a model that describes the effect of uncertainty on after-sales service decisions. We add the following assumptions to extend the model. All the notations and symbols are listed in Table 1.

\subsection{Model settings}

The following settings in our uncertainty model are equivalent to Kurata and Nam's (2010) deterministic model:

- A manufacturer decides on the level of base after-sales service that is the default for all customers, whereas a retailer determines the level of optional after-sales service that customers buy, if they wish, paying an extra fee, $r>0$, that is exogenously given.

- A retailer gains additional revenue, $r$, by selling an optional after-sales service plan to customers, whereas a manufacturer does not gain additional profit by offering a base aftersales service. 
- A market is composed of two customer segments as explained in Section 1. Segment 0 uses only the manufacturer's base service while Segment 1 buys an optional service from the retailer by paying a fixed charge, $r$ (see Figure 1).

- The retail price $p$, the wholesale price $w$, and the unit production cost $c$ are assumed exogenously fixed as $p>w>c>0$.

- Supersaturation exists in after-sales service. We assume that an offer of too much after-sales service will decrease the customer's purchase of an optional service plan.

- The demand function is maximized when the levels of a firm's after-sales service offer are equivalent to the optimal service levels, $\bar{x}$ and $\bar{y}$, that customers want the most.

- The demand function is a quadratic function regarding after-sales service levels, $x$ and $y$, that describes the optimal service level and supersaturation.

- A cost for the after-sales service offers that is proportional to the after-service levels is charged to both firms.

\section{(Insert Table 1 around here)}

Note that it is reasonable to set the price parameters, $p, r, w$, and $c$, are reasonably as fixed since this research concentrates on the effect of uncertainty on firms' after-sales service decisions. In addition, compatibility with Kurata and Nam's (2010) model is required in our paper. Moreover, a price effect is implicitly included in our model since it is safe to consider that the change of service level for the given charge $r$ changes customers' perceived cost performance.

The rationale behind the quadratic demand function is that a quadratic form is a common approach for describing such supersaturation (Hanssens et al., 2001, p. 112; Leeflang, et al., 2000, p. 68). A quadratic form is simple enough to describe that for the given after-sales service charge $r$, demand decreases as the service level becomes far from the optimal level. In addition, as analytical research, the aim of this paper is to analyze how after-sales service decisions behave in a supply chain under uncertainty, not determining the detailed structure of demand functions regarding the after-sales service level. In fact, a quadratic form has often been used in analytical research in operations management areas when formulating demands and costs (e.g., Xiao and Yang, 2008; Bernstein and Federgruen 2004; Tsay and Agrawal 2000). Although one should pay close attention to the limitations of a quadratic function form, we believe that a quadratic function is sufficient for our discussion.

\subsection{Performance measure of the after-sales service decisions}

Our model includes two best after-sales service plans that are the same as Kurata and Nam's (2010). One is an equilibrium after-sales service plan (or an equilibrium solution) determined with a Nash game model between a manufacturer and a retailer. The other is an optimal aftersales service plan (or an optimal solution) that maximizes customer satisfaction (and accordingly demand), but is unknown to firms (and, consequently, is estimated by the firms).

We set up two ideal outcomes for customers following Kurata and Nam (2010): in Ideal Type 1, the equilibrium solution is the same as the optimal solution for each firm, whereas in Ideal Type 2, the sum of two equilibrium service levels is the same as the sum of two optimal service levels. Obviously, Ideal Type 1 is stronger than Ideal Type 2. Note that the difference between the ideal solution and the optimal solution is measured using a Manhattan distance.

\section{(Insert Figure 2 around here)}


Figure 2 explains the two ideals. In Figure 2, the value of $\bar{x}+\bar{y}-x-y$, represented by the inverse-L-shaped bold line, indicates the discrepancy of the after-sales service between the firm's decisions, $x$ and $y$, and the optimal service levels, $\bar{x}$ and $\bar{y}$. Ideal Type 1 can be achieved only when the firm's after-sales service level $(x, y)$ is located exactly at point $(\bar{x}, \bar{y})$. Meanwhile, since the line A-A' in Figure 2 shows all the points where the sum of $x$ and $y$ equals $\bar{x}+\bar{y}$, then any point on the A-A' line can achieve Ideal Type 2, where the utility that customers can achieve is the same as the optimal point $(\bar{x}, \bar{y})$.

The rationale behind considering Ideal Types 1 and 2 is as follows. It is critical for modern businesses to pursue several goals simultaneously, such as customer satisfaction, sustainability, profitability, operational efficiency, compliance, etc. In our research, the firm's challenge is achieving profit maximization (i.e., a supply chain operations' goal) and customer satisfaction (i.e., a marketing goal) simultaneously. Ideal Types 1 and 2 can be used to quantitatively analyze how and when a firm can pursue important goals simultaneously. First, it would be very admirable if a firm's after-sales service decision can achieve profit maximization and customer satisfaction maximization simultaneously. This situation is what we call "Ideal Type 1" since the realization of Ideal Type 1 can fulfill two major business objectives at the same time. In a sense, Ideal Type 1 is a win-win solution for operations and marketing. Second, we assume that the effect of the after-sales service offer is additive. That is, the $x$ level of service from the retailer and the $y$ level of service from the manufacturer is equivalent in our model to the $y$ level of service from the retailer and the $x$ level of service from the manufacturer (i.e., the effect of $x+y$ is the same as that of the optimal service level $\bar{x}+\bar{y}$ as long as $x+y=\bar{x}+\bar{y}$ ). Once we assume this additive effect of the after-sales service offer on customer satisfaction, we can relax the condition of Ideal Type 1 to that of Ideal Type 2. Ideal Type 2 is a relaxed win-win solution where firms and customers can achieve the highest performance.

\subsection{Uncertainty effects and accidental outperformance}

Next, we explain several modeling features that are new to this uncertainty paper.

\subsubsection{Uncertainty effects}

The uncertainty of a firm's realization of customer needs for after-sales service is modeled as follows:

- The demand is maximized at the optimal service levels, $\bar{x}$ and $\bar{y}$, but these optimal service levels are assumed to be unknown to the firms. Then, each firm estimates the optimal aftersales service levels, $\hat{x}$ and $\hat{y}$.

- A uniform distribution is assumed for the estimated optimal after-service level, that is, $\hat{x} \sim \operatorname{Uni}\left(\bar{x}-\varepsilon_{x}, \bar{x}+\varepsilon_{x}\right)$ and $\hat{y} \sim U n i\left(\bar{y}-\varepsilon_{y}, \bar{y}+\varepsilon_{y}\right)$, where $\varepsilon_{x} \geq 0$ and $\varepsilon_{y} \geq 0$.

- $\quad \varepsilon_{x}$ and $\varepsilon_{y}$ are assumed to be small enough not to make the estimation negative.

- Given the estimated optimal service level (i.e., $\hat{x}$ for a manufacturer and $\hat{y}$ for a retailer), each firm determines an after-sales service level that will maximize its expected profit (i.e., $x^{*}$ for a manufacturer and $y^{*}$ for a retailer).

- The discrepancy between the estimation and the real optimal level for that estimation is denoted by $\delta_{x}$ and $\delta_{y}$ such that $\hat{x}=\bar{x}+\delta_{x}$ and $\hat{y}=\bar{y}+\delta_{y} . \delta_{x}$ and $\delta_{y}$ are referred to as estimation-realization gaps hereafter. 
Figure 3, using a manufacturer as an example, illustrates the decision procedure for after-sales service under uncertainty. Note that analytical modeling often uses uniform distribution for an unobservable parameter. Rigorous justification for applying uniform distribution for an uncertain parameter was provided by Barmish and Lagoa (1997).

\subsubsection{Accidental outperformance}

Another key concept in this paper is accidental outperformance. Kurata and Nam (2010) showed that, in a certainty model, the equilibrium service level at which the firm can maximize its profit tends to be smaller than the optimal service level that the customers prefer the most. However, in Section 4 an after-sales service level in the uncertainty model in this paper is greater or smaller than that of the certainty model. This means that there is a chance that an under-offer of after-sales service in the certainty case will be cancelled out by the uncertainty effect. In other words, there might be a case where a firm's under-offer of after-sales service to customers (i.e., the first error) will be mitigated accidentally by the gap between the uncertainty and certainty models due to uncertainty (i.e., the second error). We call this type of lucky occurrence accidental outperformance. Of course, the better result for the uncertainty case compared to the certainty case is not a reasonable decision, just luck. However, the firm might misunderstand the lucky occurrence as a rational decision and thus continue with a less appropriate service plan without knowing the truth. In Section 4, we explore the risk of not recognizing an erroneous decision.

\section{(Insert Figure 3 around here)}

\subsection{Several information structures related to uncertainty}

The uncertainty model in Section 2.3 (Case 1: Base model, hereafter) assumes that neither the manufacturer nor the retailer knows the customer's optimal level for either base or optional aftersales services. However, one can reasonably assume other settings of uncertainty. For example, it is natural to assume that a retailer has a larger amount of data on customer behavior than the manufacturer. One can also assume that a retailer has information about an optional after-sales service under the retailer's control but does not have information about the base service that the retailer cannot control, and vice versa for a manufacturer. Considering several possible circumstances of information availability, we developed several different models to investigate the effect of information structure in a supply chain under uncertainty:

Case 0 (Certainty Case): Case 0 is Kurata and Nam's (2010) base model in which both firms know the customer's optimal after-sales service levels. Each firm determines the equilibrium service level under the Nash game framework. The certainty model is first compared with our base model to examine the effect of uncertainty.

Case 1 (Uncertainty Case: Base Model): Case 1 is the base model of this paper. In Case 1, we assume that neither the manufacturer nor the retailer knows the customer's real needs for after-sales service. The firm determines the most profitable after-sales service level using the customers' estimated optimal after-sales service levels, $\hat{x}$ and $\hat{y}$. A Nash game determines the firms' decisions. The Case 1 results will be compared with the other cases.

Case 2 (Uncertainty Case with Unknown Optional Service): In Case 2, we assume that information about the base after-sales service is known to the manufacturer and the retailer, but they do not know the customers' real optional after-sales service needs. This model 
reflects a situation where information on the base after-sales service is well known (perhaps such information is widely researched by practitioners and researchers), but the retailer keeps its information about optional after-sales service private (perhaps the retailer is concerned about losing its competency by leaking the information).

Case 3 (Uncertainty Case with Knowledgeable Retailer I): In Case 3, we assume that a retailer that is close to its customers has information about their needs for default and optional after-sales service, but the manufacturer does not know about customers' real needs for after-sales service. This type of information setting is common in supply chain articles (e.g., customer demand information is available only to the retailer, not to the manufacturer). Case 4 (Uncertainty Case with Knowledgeable Retailer II): Case 4 is a revision of Case 3. In Case 4, we assume that a retailer and a manufacturer have information about an optimal base after-sales service, while in Case 3 the information about customers' needs for the optional after-sales service is available only to the retailer.

Case 5 (Uncertainty Case with Mutuality): In Case 5, we assume that the manufacturer has information only about the base after-service level, while the retailer has information only about the optional after-sales service level. That is, Case 5 assumes that each firm has information about the after-sales service that the firm controls, but neither company has information about the after-sales service the opposite firm controls.

Table 2 summarizes the information structures in a supply chain for the six cases above.

\section{(Insert Table 2 around here)}

\subsection{Demand and profit functions}

A demand function in this paper is the same as that in Kurata and Nam's work (2010) except that a firm uses an estimated optimal service level $(\hat{x}$ and $\hat{y})$ instead of a real optimal service level $(\bar{x}$ and $\bar{y}$ ) because it is often difficult for a firm to perfectly understand customers' preference. In our base model (Case 1), a demand function for Segment 0 is defined as

$$
d_{0}=d_{0}(x) \equiv a_{0}+b_{0} x(2 \hat{x}-x) \text {. }
$$

In addition, a demand function for Segment 1 is defined as

$$
d_{1}=d_{1}(x, y)=a_{1}+b_{1}(x+y)(2 \hat{x}+2 \hat{y}-x-y) .
$$

Customers in Segment 1 are assumed to recognize the sum of the manufacturer's basic aftersales service $(x)$ and the retailer's optional after-sales service $(y)$ as the total perceived service level, which determines demand.

Since one can assume that the retail price, wholesale price, unit production cost, and additional unit revenue from an optional service plan are exogenously fixed, then a manufacturer's unit profit is determined as $w-c$ while a retailer's unit profit is decided as $p-w$ for Segment 0 and $p+r-w$ for Segment 1. Moreover, the cost for offering after-sales services is proportional to the level of service offered. Consequently, profit functions are determined for the base model (Case 1) as follows:

For a retailer,

$$
\begin{aligned}
\pi_{R}^{1}(y \mid x)=( & p-w)\left\{a_{0}+b_{0} x(2 \hat{x}-x)\right\} \\
& +(p+r-w)\left\{a_{1}+b_{1}(x+y)(2 \hat{x}+2 \hat{y}-x-y)\right\}-k_{R} y,
\end{aligned}
$$

and for a manufacturer,

$$
\pi_{M}^{1}(x \mid y)=(w-c)\left\{a_{0}+b_{0} x(2 \hat{x}-x)+a_{1}+b_{1}(x+y)(2 \hat{x}+2 \hat{y}-x-y)\right\}-k_{M} x .
$$


Note that the superscript "1" indicates Case 1. In general, the superscript " $m$ " represents Case " $m$ " in this paper.

\section{Effect of information structures on after-sales service decisions}

The assumption of uniform distributions for a firm's estimation of optimal after-service levels guarantees unbiasness: in the long run, the expected value of the after-sales service level would be equivalent to the one that is optimal for customers. However, in practice, a company rarely revises an after-sales service decision (e.g., the length of a free product warranty). Therefore, it is reasonable that the gap between the firm's estimation $(\hat{x}$ or $\hat{y})$ and the real value $(\bar{x}$ or $\bar{y})$ influences the firm's service decision. We then represent such gaps between estimation and reality using symbols, $\delta_{x}$ and $\delta_{y}$, where

$$
\begin{aligned}
& \hat{x}=\bar{x}+\delta_{x} \text { and } \\
& \hat{y}=\bar{y}+\delta_{y} .
\end{aligned}
$$

Note that $\delta_{x}=\delta_{y}=0$ implies the certainty model (Case 0 ). This section first explores whether each ideal type is achieved under uncertainty and how ideal types, if achieved, behave regarding the estimation-realization gaps $\delta_{x}$ and $\delta_{y}$.

\subsection{Analysis of the base model (Case 1)}

Using the estimation gaps (3) and (4), the profit functions (1) and (2) can be rewritten as:

For a retailer, $\pi_{R}^{1}(y \mid x)=(p-w)\left\{a_{0}+b_{0} x(2 \bar{x}-x)\right\}$

$$
\begin{aligned}
& +(p+r-w)\left\{a_{1}+b_{1}(x+y)(2 \bar{x}+2 \bar{y}-x-y)\right\}-k_{R} y \\
& +\left\{2 b_{0}(p-w) x+2 b_{1}(p+r-w)(x+y)\right\} \delta_{x}+2 b_{1}(p+r-w)(x+y) \delta_{y},
\end{aligned}
$$

and for a manufacturer,

$$
\begin{aligned}
& \pi_{M}^{1}(x \mid y)=(w-c)\left\{a_{0}+b_{0} x(2 \bar{x}-x)+a_{1}+b_{1}(x+y)(2 \bar{x}+2 \bar{y}-x-y)\right\}-k_{M} x . \\
& +\left\{2 b_{0}(w-c) x+2 b_{1}(w-c)(x+y)\right\} \delta_{x}+2 b_{1}(w-c)(x+y) \delta_{y} .
\end{aligned}
$$

Solving the derivatives of Equations (5) and (6) simultaneously, we obtain the Nash solution of the base model (Case 1) as Proposition 1 shows.

\section{Proposition 1.}

For the base uncertainty model (Case 1),

(a) The Nash solution for equilibrium after-sales service levels of the base model is

$$
\begin{aligned}
& x^{1^{*}}=\bar{x}+\delta_{x}+\frac{k_{R}}{2 b_{0}(p+r-w)}-\frac{k_{M}}{2 b_{0}(w-c)}, \\
& y^{1^{*}}=\bar{y}+\delta_{y}-\frac{k_{R}\left(b_{0}+b_{1}\right)}{2 b_{0} b_{1}(p+r-w)}+\frac{k_{M}}{2 b_{0}(w-c)} .
\end{aligned}
$$

(b) Ideal Type 1 is achieved when

$$
\begin{aligned}
& \delta_{x}=-\frac{k_{R}}{2 b_{0}(p+r-w)}+\frac{k_{M}}{2 b_{0}(w-c)} \text { and } \\
& \delta_{y}=\frac{\left(b_{0}+b_{1}\right) k_{R}}{2 b_{0} b_{1}(p+r-w)}-\frac{k_{M}}{2 b_{0}(w-c)} .
\end{aligned}
$$

(c) Ideal Type 2 is achieved when $\delta_{x}+\delta_{y}=\frac{k_{R}}{2 b_{1}(p+r-w)}$.

Proof: All proofs are included in the appendix. 
First, if one deletes the estimation gaps, $\delta_{x}$ and $\delta_{y}$, from Equations (7) and (8), the Nash solution in Proposition 1 will be the same as the Nash solution in Case 0 , that is, the solution under certainty proved by Kurata and Nam (2010). Second, Proposition 1 proves the possibility that Ideal Types 1 and 2 can be achieved, even under uncertainty. Interestingly, the right-hand side of (9) is composed of only the parameters related to the retailer's decisions. This implies that a retailer plays a more significant role than a manufacturer if a supply chain aims at achieving simultaneous profit maximization and customer satisfaction. Finally, and most importantly, since each $\delta_{x}$ or $\delta_{y}$ may take either a positive or negative value within the range of the given uniform distribution, a chance for accidental outperformance may exist. That is, estimation errors may make the firm's service decision under uncertainty closer to the optimal after-sales service level than the decision under certainty. Note that such an accidental after-sales service improvement due to information uncertainty never means that a firm's understanding of customers' real needs is unnecessary. Instead, accidental outperformance means that making a second mistake (i.e., estimation errors in the uncertainty model) might accidentally offset some portion of the negative impact of the first mistake (i.e., a tendency to under-service in the certainty case). Moreover, an accidental outperformance might hide the fact that the firm misunderstands customers' real needs for after-sales service, and thus, an appropriate reaction to adjust the firm's after-sales policy might be delayed. In Section 4, we consider the likelihood of such an accidental outperformance in firms' after-sales service decisions.

\subsection{Analysis of Case 2, the Uncertainty Case with Unknown Optional Service.}

In the remaining subsections in Section 3, we compare the impacts of asymmetric information structures in a supply chain on firms' after-sales service decisions. In Subsection 3.2, we compare the base model (i.e., Case 1) with Case 2 where the firms do not have information about the optimal level of an optional service but information regarding base service is known to both companies.

\section{Proposition 2. Analysis of Case 2.}

(a) For Case 2, the Nash solution is determined as,

$$
\begin{aligned}
& x^{2 *}=\bar{x}+\frac{k_{R}}{2 b_{0}(p+r-w)}-\frac{k_{M}}{2 b_{0}(w-c)}, \\
& y^{2 *}=\bar{y}+\delta_{y}-\frac{\left(b_{0}+b_{1}\right) k_{R}}{2 b_{0} b_{1}(p+r-w)}+\frac{k_{M}}{2 b_{0}(w-c)} .
\end{aligned}
$$

(b) Ideal Type 1 is achieved if

$$
\begin{aligned}
& \frac{k_{R}}{2 b_{0}(p+r-w)}-\frac{k_{M}}{2 b_{0}(w-c)}=0 \text { and } \\
& \delta_{y}=\frac{\left(b_{0}+b_{1}\right) k_{R}}{2 b_{0} b_{1}(p+r-w)}-\frac{k_{M}}{2 b_{0}(w-c)} .
\end{aligned}
$$

(c) Ideal Type 2 is achieved if

$$
\delta_{y}=\frac{k_{R}}{2 b_{1}(p+r-w)} .
$$

We know from Proposition 2 that as long as information about the base service is known, the manufacturer's equilibrium service decision in Case 2 is independent of the uncertainty of an optional after-sales service, since only an estimation-realization gap $\delta_{y}$ appears in (11). Proposition 2 also indicates that in Case 2 there is a chance that Ideal Types 1 and 2 can be achieved. Moreover, Proposition 2 (c) proves that only a retailer can set the conditions for Ideal Type 2 because the RHS of (14) contains parameters associated with the retailer. 


\subsection{Analysis of Cases 3 and 4, the Uncertainty Cases with Knowledgeable Retailer.} In this subsection, we consider Cases 3 and 4, the knowledgeable retailer cases, where a retailer is assumed to know customers' optimal levels of the base and the optional after-sales service offers, while a manufacturer either does not know both services in Case 3 or knows only the base optional service level in Case 4.

\section{Proposition 3. Analysis of Cases 3 and 4.}

(a) For Case 3, the Nash solution is determined as,

$$
\begin{aligned}
& x^{3 *}=\bar{x}+\frac{b_{0}+b_{1}}{b_{0}} \cdot \delta_{x}+\frac{b_{1}}{b_{0}} \cdot \delta_{y}+\frac{k_{R}}{2 b_{0}(p+r-w)}-\frac{k_{M}}{2 b_{0}(w-c)}, \\
& y^{3 *}=\bar{y}-\frac{b_{0}+b_{1}}{b_{0}} \cdot \delta_{x}-\frac{b_{1}}{b_{0}} \cdot \delta_{y}-\frac{\left(b_{0}+b_{1}\right) k_{R}}{2 b_{0} b_{1}(p+r-w)}+\frac{k_{M}}{2 b_{0}(w-c)} .
\end{aligned}
$$

(b) Ideal Type 1 is not achieved in Case 3.

(c) Ideal Type 2 is not achieved in Case 3 since $x^{3 *}+y^{3 *}=\bar{x}+\bar{y}-\frac{k_{R}}{2 b_{1}(p+r-w)}<\bar{x}+\bar{y}$.

(d) For Case 4, the Nash solution is determined as,

$$
\begin{aligned}
& x^{4 *}=\bar{x}+\frac{b_{1}}{b_{0}} \cdot \delta_{y}+\frac{k_{R}}{2 b_{0}(p+r-w)}-\frac{k_{M}}{2 b_{0}(w-c)}, \\
& y^{4 *}=\bar{y}-\frac{b_{1}}{b_{0}} \cdot \delta_{y}-\frac{\left(b_{0}+b_{1}\right) k_{R}}{2 b_{0} b_{1}(p+r-w)}+\frac{k_{M}}{2 b_{0}(w-c)} .
\end{aligned}
$$

(e) Ideal Type 1 is not achieved in Case 4.

(f) Ideal Type 2 is not achieved in Case 4 since $x^{4 *}+y^{4 *}=\bar{x}+\bar{y}-\frac{k_{R}}{2 b_{1}(p+r-w)}<\bar{x}+\bar{y}$.

Proposition 3 proves that there is no possibility for a supply chain to achieve either Ideal Type 1 or Ideal Type 2 in the knowledgeable retailer cases. In addition, Propositions 3 (c) and (f) present interesting managerial advice: Once a retailer has information about customers' real needs for after-sales service, there is no possibility of "accidental outperformance." That is, the equilibrium service level in the knowledgeable retailer is always under-served. Another finding is that a manufacturer's knowledge or lack of it regarding customers' needs for after-sales service is irrelevant to success or failure in achieving an ideal situation.

\subsection{Analysis of Case 5, the Uncertainty Case with Mutuality.}

In this subsection, we analyze the case where each firm has only after-sales service information that the firm itself can control.

Proposition 4. Analysis of Case 5, the Uncertainty Case with Mutuality.

(a) For Case 5, the Nash solution is determined as,

$$
\begin{aligned}
& x^{5 *}=\bar{x}+\frac{k_{R}}{2 b_{0}(p+r-w)}-\frac{k_{M}}{2 b_{0}(w-c)}-\frac{b_{1}}{b_{0}} \cdot \delta_{x}+\frac{b_{1}}{b_{0}} \cdot \delta_{y}, \\
& y^{5 *}=\bar{y}-\frac{\left(b_{0}+b_{1}\right) k_{R}}{2 b_{0} b_{1}(p+r-w)}+\frac{k_{M}}{2 b_{0}(w-c)}+\frac{b_{0}+b_{1}}{b_{0}} \cdot \delta_{x}-\frac{b_{1}}{b_{0}} \cdot \delta_{y}
\end{aligned}
$$

(b) Ideal Type 1 is achieved if

$$
\begin{aligned}
& \delta_{x}=\frac{k_{R}}{2 b_{1}(p+r-w)} \text { and } \\
& \delta_{y}=\frac{k_{M}}{2 b_{1}(w-c)} .
\end{aligned}
$$

(c) Ideal Type 2 is achieved if

$$
\delta_{x}=\frac{k_{R}}{2 b_{1}(p+r-w)} .
$$


It is known from Proposition 4 (c) that a firm's knowledge of its own after-sales service will not eliminate the possibility of accidental outperformance. In addition, Proposition 4 (c) shows that only an estimation error by a manufacturer can influence the possibility of achieving Ideal Type 2. Table 3 summarizes the results in Section 3.

\section{(Insert Table 3 around here)}

\section{Impact of estimation rrrors on a firm's after-sales service decisions}

When estimating the optimal after-sales service levels, $\bar{x}$ and $\bar{y}$, a firm makes estimation errors, $\delta_{x}$ and $\delta_{y}$. Focusing on the base uncertainty model (Case 1), in this section we study how likely it is the estimation errors will lead a firm to misunderstand its less appropriate after-sales service decision under uncertainty as a more appropriate decision than it actually is. Note that we measure the intensity of the misunderstanding by the distance between the sum of the optimal levels and the sum of the equilibrium levels, $\left|x^{1 *}+y^{1 *}-\bar{x}-\bar{y}\right|$. Note that zero distance is Ideal Type 2.

Kurata and Nam (2010) presented that, for the certainty case (Case 0), the Nash solution is always under-serviced:

$$
x^{0 *}+y^{0 *}-\bar{x}-\bar{y}=-\frac{k_{R}}{2 b_{1}(p+r-w)}<0 .
$$

From the proof of Proposition 1 (c), the distance of Case 1, when the estimation gaps are $\delta_{x}$ and $\delta_{y}$, is expressed as follows:

$$
x^{1 *}+y^{1 *}-\bar{x}-\bar{y}=\delta_{x}+\delta_{y}-\frac{k_{R}}{2 b_{1}(p+r-w)} .
$$

Hence, if $0<\delta_{x}+\delta_{y}<\frac{k_{R}}{b_{1}(p+r-w)}$, then accidental outperformance of the service level occurs

because $\left|x^{1 *}+y^{1 *}-\bar{x}-\bar{y}\right|<\frac{k_{R}}{2 b_{1}(p+r-w)}=\left|x^{0 *}+y^{0 *}-\bar{x}-\bar{y}\right|$

\section{(Insert Figure 4 around here)}

Figure 4 graphically explains Equation (17), that is, the condition under which accidental outperformance occurs. In Figure 4, the line A-A' represents Equation (18), the area bordered by the dotted square $\mathrm{S}_{1}-\mathrm{S}_{2}-\mathrm{S}_{3}-\mathrm{S}_{4}$ illustrates the feasible region of $\delta_{x}$ and $\delta_{y}$ (i.e., Condition (19)), and the lines B-B' and C-C' represent Equations (20) and (21), respectively:

$$
\begin{aligned}
& \delta_{x}+\delta_{y}=\frac{k_{R}}{2 b_{1}(p+r-w)}, \\
& \delta_{x} \in\left[-\varepsilon_{x}, \varepsilon_{x}\right] \text { and } \delta_{y} \in\left[-\varepsilon_{y}, \varepsilon_{y}\right] . \\
& \delta_{x}+\delta_{y}=\frac{k_{R}}{b_{1}(p+r-w)}, \text { and } \\
& \delta_{x}+\delta_{y}=0 .
\end{aligned}
$$

It is apparent that if the estimation-realization gaps, $\delta_{x}$ and $\delta_{y}$, are located in the area between the lines B-B' and C-C' (i.e., the shaded area $\mathrm{M}_{1}-\mathrm{M}_{2}-\mathrm{M}_{3}-\mathrm{S}_{4}-\mathrm{M}_{4}$ in Figure 4), then accidental outperformance occurs since the distance of Case 1 is less than that of Case 0 . Therefore, the probability that accidental outperformance occurs for certain estimation-realization gaps $\delta_{x}$ and $\delta_{y}$ can be calculated with the ratio of the area determined by Equation (17) to the feasible area of $\delta_{x}$ and $\delta_{y}$. Note that the area determined by Equation (17) is redefined by Condition (19), 


$$
\begin{aligned}
& \delta_{x}+\delta_{y} \leq \frac{k_{R}}{b_{1}(p+r-w)}, \text { and } \\
& \delta_{x}+\delta_{y} \geq 0 .
\end{aligned}
$$

Proposition 5 summarizes the probability that accidental outperformance of the service level occurs due to uncertainty.

\section{Proposition 5.}

For certain estimation errors, the probability that accidental outperformance occurs (i.e., the total after-sales service level of the uncertainty case is closer to the total optimal after-service level than that of the certainty case) is determined as follows:

(1) When $\varepsilon_{x} \geq \varepsilon_{y}$,

(a) If $K \geq \varepsilon_{x}+\varepsilon_{y}, \operatorname{Prob}\left(x^{1 *}+y^{1 *}>x^{0 *}+y^{0 *}\right)=0.5$,

(b) If $\varepsilon_{x}+\varepsilon_{y}>K \geq \varepsilon_{x}-\varepsilon_{y}$, $\operatorname{Prob}\left(x^{1 *}+y^{1 *}>x^{0 *}+y^{0 *}\right)=0.5-\frac{\left(\varepsilon_{x}+\varepsilon_{y}-K\right)^{2}}{8 \varepsilon_{x} \varepsilon_{y}}$, and

(c) If $\varepsilon_{x}-\varepsilon_{y}>K>0, \operatorname{Prob}\left(x^{1 *}+y^{1 *}>x^{0 *}+y^{0 *}\right)=\frac{K}{2 \varepsilon_{x}}$.

(2) When $\varepsilon_{y}>\varepsilon_{x}$,

(a) If $K \geq \varepsilon_{x}+\varepsilon_{y}, \operatorname{Prob}\left(x^{1 *}+y^{1 *}>x^{0 *}+y^{0 *}\right)=0.5$,

(b) If $\varepsilon_{x}+\varepsilon_{y}>K \geq \varepsilon_{y}-\varepsilon_{x}$, $\operatorname{Prob}\left(x^{1 *}+y^{1 *}>x^{0 *}+y^{0 *}\right)=0.5-\frac{\left(\varepsilon_{x}+\varepsilon_{y}-K\right)^{2}}{8 \varepsilon_{x} \varepsilon_{y}}$, and

(c) If $\varepsilon_{y}-\varepsilon_{x}>K>0, \operatorname{Prob}\left(x^{1 *}+y^{1 *}>x^{0 *}+y^{0 *}\right)=\frac{K}{2 \varepsilon_{y}}$.

where $K=\frac{k_{R}}{2 b_{1}(p+r-w)}$, and $\varepsilon_{x}$ and $\varepsilon_{y}$ are the given ranges of the uniform distribution for the estimated after-sales service levels.

Note once again that accidental outperformance of the service level is not a real improvement but just an accidental occurrence; when the estimation-realization gaps satisfy Condition (17) by chance, the equilibrium service levels become close to the customers' optimal levels. Of course, there also exists a chance that the estimation errors will worsen the company's decisions under uncertainty lower than the certainty case.

Next we analyze how uncertainty represented by $\delta_{x}$ and $\delta_{y}$ influences the total profit of the supply chain, $\pi_{M}^{1 *}+\pi_{R}^{1 *}$. Since the profit maximization decision under uncertainty depends on the preference estimation, estimation errors might make the total profit calculation of the uncertainty case higher than that of the certainty case (hereafter, we call this outcome accidental outperformance of the total profit). Proposition 6 presents the probability that accidental outperformance of the total profit occurs for certain estimation errors.

\section{Proposition 6.}

For certain estimation errors, the probability that accidental outperformance of the total profit (i.e., the total profit of the uncertainty case is more than that of the certainty case) will occur is determined as 0.5. That is,

$$
\operatorname{Prob}\left(\pi_{M}^{1 *}+\pi_{R}^{1 *}>\pi_{M}^{0 *}+\pi_{R}^{0 *}\right)=0.5
$$

Proposition 6 proposes an intuitive outcome; uncertainty makes the total profit of the supply chain more or less than the level of the certainty case by 50-50 chance. One-time luck may result 
in accidental outperformance of the total profit, but in the long run, the expected profit of the uncertainty case will be the same as that of the certainty case.

Next, we consider the situation in which estimation errors improve the total after-sales service level and the total profit of the supply chain. Proposition 7 states the probability that uncertainty will positively affect the service level and profit.

\section{Proposition 7.}

For certain estimations, the probability that accidental outperformance in the total service level (i.e. , $x^{1 *}+y^{1 *}>x^{0 *}+y^{0 *}$ ) and accidental outperformance of the total profit (i.e., $\pi_{M}^{1 *}+$ $\left.\pi_{R}^{1 *}>\pi_{M}^{0 *}+\pi_{R}^{0 *}\right)$ occur is determined as follows:

(1) When $\varepsilon_{x} \geq \varepsilon_{y}$,

(a) If $K \geq \varepsilon_{x}+\varepsilon_{y}$,

$$
\operatorname{Prob}\left(x^{1 *}+y^{1 *}>x^{0 *}+y^{0 *} \text { and } \pi_{M}^{1 *}+\pi_{R}^{1 *}>\pi_{M}^{0 *}+\pi_{R}^{0 *}\right)=0.5-\frac{\varepsilon_{y}}{8 \varepsilon_{x}}(1-1 / S),
$$

(b) If $\varepsilon_{x}+\varepsilon_{y}>K \geq \varepsilon_{x}-\varepsilon_{y}$,

$$
\begin{aligned}
& \operatorname{Prob}\left(x^{1 *}+y^{1 *}>x^{0 *}+y^{0 *} \text { and } \pi_{M}^{1 *}+\pi_{R}^{1 *}>\pi_{M}^{0 *}+\pi_{R}^{0 *}\right)=0.5-\frac{\left(\varepsilon_{x}+\varepsilon_{y}-K\right)^{2}}{8 \varepsilon_{x} \varepsilon_{y}}- \\
& \frac{\varepsilon_{y}}{8 \varepsilon_{x}}(1-1 / S),
\end{aligned}
$$

(c) If $\varepsilon_{x}-\varepsilon_{y}>K>0$ and $\frac{S K}{S-1} \geq \varepsilon_{y}$

$\operatorname{Prob}\left(x^{1 *}+y^{1 *}>x^{0 *}+y^{0 *}\right.$ and $\left.\pi_{M}^{1 *}+\pi_{R}^{1 *}>\pi_{M}^{0 *}+\pi_{R}^{0 *}\right)=\frac{K}{2 \varepsilon_{x}}-\frac{\varepsilon_{y}}{8 \varepsilon_{x}}(1-1 / S)$, and

(d) If $\varepsilon_{x}-\varepsilon_{y}>K>0$ and $\frac{S K}{S-1}<\varepsilon_{y}$,

$$
\operatorname{Prob}\left(x^{1 *}+y^{1 *}>x^{0 *}+y^{0 *} \text { and } \pi_{M}^{1 *}+\pi_{R}^{1 *}>\pi_{M}^{0 *}+\pi_{R}^{0 *}\right)=\frac{K}{4 \varepsilon_{x}}+\frac{S K^{2}}{8(S-1) \varepsilon_{x} \varepsilon_{y}} .
$$

(2) When $\varepsilon_{y}>\varepsilon_{x}$,

(a) If $S \varepsilon_{x} \leq \varepsilon_{y}$ and $K \geq \varepsilon_{x}+\varepsilon_{y}$,

$$
\operatorname{Prob}\left(x^{1 *}+y^{1 *}>x^{0 *}+y^{0 *} \text { and } \pi_{M}^{1 *}+\pi_{R}^{1 *}>\pi_{M}^{0 *}+\pi_{R}^{0 *}\right)=0.5+\frac{\varepsilon_{x}}{8 \varepsilon_{y}}(1-S),
$$

(b) If $S \varepsilon_{x}>\varepsilon_{y}$ and $K \geq \varepsilon_{x}+\varepsilon_{y}$,

$$
\operatorname{Prob}\left(x^{1 *}+y^{1 *}>x^{0 *}+y^{0 *} \text { and } \pi_{M}^{1 *}+\pi_{R}^{1 *}>\pi_{M}^{0 *}+\pi_{R}^{0 *}\right)=\frac{1}{4}+\frac{\varepsilon_{y}}{8 \varepsilon_{x} S}+\frac{\varepsilon_{x}}{8 \varepsilon_{y}},
$$

(c) If $S \varepsilon_{x} \leq \varepsilon_{y}$ and $\varepsilon_{x}+\varepsilon_{y}>K \geq \varepsilon_{y}-\varepsilon_{x}$,

$$
\operatorname{Prob}\left(x^{1 *}+y^{1 *}>x^{0 *}+y^{0 *} \text { and } \pi_{M}^{1 *}+\pi_{R}^{1 *}>\pi_{M}^{0 *}+\pi_{R}^{0 *}\right)=0.5+\frac{\varepsilon_{x}}{8 \varepsilon_{y}}(1-S)-
$$

$$
\frac{\left(\varepsilon_{x}+\varepsilon_{y}-K\right)^{2}}{8 \varepsilon_{x} \varepsilon_{y}}
$$

(d)If $S \varepsilon_{x}>\varepsilon_{y}$ and $\varepsilon_{x}+\varepsilon_{y}>K \geq \varepsilon_{y}-\varepsilon_{x}$,

$$
\operatorname{Prob}\left(x^{1 *}+y^{1 *}>x^{0 *}+y^{0 *} \text { and } \pi_{M}^{1 *}+\pi_{R}^{1 *}>\pi_{M}^{0 *}+\pi_{R}^{0 *}\right)=\frac{1}{4}+\frac{\varepsilon_{y}}{8 \varepsilon_{x} S}+\frac{\varepsilon_{x}}{8 \varepsilon_{y}}-
$$

$$
\frac{\left(\varepsilon_{x}+\varepsilon_{y}-K\right)^{2}}{8 \varepsilon_{x} \varepsilon_{y}}
$$

(e) If $\varepsilon_{y}-\varepsilon_{x}>K \geq(S-1) \varepsilon_{x}, \operatorname{Prob}\left(x^{1 *}+y^{1 *}>x^{0 *}+y^{0 *}\right.$ and $\left.\pi_{M}^{1 *}+\pi_{R}^{1 *}>\pi_{M}^{0 *}+\pi_{R}^{0 *}\right)$

$$
=\frac{K}{2 \varepsilon_{y}}+\frac{\varepsilon_{x}}{8 \varepsilon_{y}}(1-S), \text { and }
$$


(f) If $(S-1) \varepsilon_{x}>K, \operatorname{Prob}\left(x^{1 *}+y^{1 *}>x^{0 *}+y^{0 *}\right.$ and $\left.\pi_{M}^{1 *}+\pi_{R}^{1 *}>\pi_{M}^{0 *}+\pi_{R}^{0 *}\right)=$ $\frac{K^{2}}{8 \varepsilon_{x} \varepsilon_{y}(S-1)}+\frac{K}{4 \varepsilon_{y}}$.

where $K=\frac{k_{R}}{2 b_{1}(p+r-w)}, S=\frac{\partial\left(\pi_{M}+\pi_{R}\right) / \partial \delta_{x}}{\partial\left(\pi_{M}+\pi_{R}\right) / \partial \delta_{y}}>1$, and $\varepsilon_{x}$ and $\varepsilon_{y}$ are the given ranges of the uniform distribution for the estimated after-sales service levels.

One finding from Proposition 7 is that the probability of accidental outperformance occurrence increases as uncertainty levels decrease. In other words, the more exactly a firm understands customers' hidden preferences for after-sales service (perhaps by conducting intensive marketing research), the more likely the firm is to misjudge its incorrect after-sales service decision as appropriate, and consequently, the firm would be delayed in adjusting its after-sales service policies. Using a numerical approach, in the next section we discuss the likelihood of accidental outperformance.

\section{Numerical examples and managerial implications}

In this section, we illustrate numerically how an uncertainty level (i.e., the half ranges of uniform distributions, $\varepsilon_{x}$ and $\varepsilon_{y}$ ) influence the probability of accidental outperformance. After using numerical illustrations, we propose several managerial implications derived from the analytical results.

As a visual explanation of Proposition 7, Figure 5 demonstrates the effect of $\varepsilon_{x}$ on the probability that accidental outperformance of the total service level and the total profit will occur. Note that the numerical example for Figure 5 arbitrarily sets the parameters as $K=S=2$ and $\varepsilon_{y}=0.5 \varepsilon_{x}$.

\section{(Insert Figure 5 around here)}

Figure 5 shows that the probability of accidental outperformance of the service level starts from 0.5 when $\varepsilon_{x}$ is small enough. However, from a certain threshold point the probability decreases as the uncertainty level (i.e., $\varepsilon_{x}$ ) increases. Meanwhile, the probability of accidental outperformance of the total profit remains 0.5 over any uncertainty level. This leads to an ironic managerial insight: As a firm improves the accuracy of customers' after-sales service preference estimation, the firm will more likely misunderstand its incorrect after-sales service policy as appropriate. Companies always make every effort to understand their customers. However, once the firm succeeds in estimating the preference more accurately than before, the firm's efforts might cause another risk that the firm could misunderstand an accidental improvement in the after-sales service policy as a correct decision. Note that accidental outperformance is critical in real business in the short run since even if the after-sales service estimation is unbiased, companies (e.g., electronic appliances and personal computer firms) do not frequently revise their after-sales service policies.

Next, we consider how the $K$ and $S$ values influence the after-sales service decision. Note that the value of $K=\frac{k_{R}}{2 b_{1}(p+r-w)}$ can be understood as the efficiency of a retailer's optional after-sales service offer since the numerator of $K$ is $k_{R}$, a unit cost of offering an optional after-sales service, and the denominator, $2 b_{1}(p+r-w)$, is a function of the marginal revenue of selling an 
optional after-sales service. In addition, the value of $S=\frac{\partial\left(\pi_{M}+\pi_{R}\right) / \partial \delta_{x}}{\partial\left(\pi_{M}+\pi_{R}\right) / \partial \delta_{y}}$ is defined as the ratio of the impact of a basic after-sales service estimation error to the impact of an optional after-sales service estimation error, with respect to the total profit. Therefore, $S$ can be interpreted as the robustness of the retailer's optional after-sales service operations in response to the uncertainty. Higher $S$ values imply the retailer has more robust service operations. Figure 6 illustrates the sensitivity analysis of Proposition 7, the effect of changes in $K$ and $S$ on the probability of accidental outperformance in the service level and the total profit.

Figure 6 shows that the probability of accidental outperformance increases in $K$ but decreases in $S$. The $K$ and $S$ values can be interpreted as the efficiency and the robustness of a retailer's optional after-sales service operations, respectively, in uncertainty. Therefore, if a retailer makes every effort to improve the efficiency of the after-sales service operations (i.e., higher $K$ ), the probability of accidental outperformance will be exaggerated. However, if the retailer's optional service operations are designed to be less sensitive to estimation errors (i.e., higher $S$ ), then the probability of accidental outperformance decreases. This result is interesting; on one hand, a firm's efforts in improving its after-sales service contribute to high efficiency in operations, but on the other hand, these efforts are likely to result in a firm confusing an accidentally outperformed decision with an appropriate one.

\section{(Insert Figure 6 around here)}

\section{Managerial insights.}

The analytical findings in this paper lead to several managerial insights into after-sales service in a supply chain.

(1) Significant role of retailers in after-sales service: Although a manufacturer and a retailer offer after-sales services to customers, the decision to offer adequate after-sales services to customers depends more on the retailer than on the manufacturer.

(2) Accidental outperformance due to estimation error: Estimation errors in capturing customers' needs for after-sales service may cause what we call accidental outperformance. That is, due to incorrect estimation, the firm's service decision under uncertainty becomes accidentally closer to the optimal after-sales service level than the decision under certainty.

(3) Concealment effect of accidental outperformance: An accidental outperformance might hide the fact that the firm misunderstands customers' real needs for after-sales service, and thus, the firm might not appropriately adjust its after-sales policy in a timely manner.

(4) Side effect of accurate estimation: The risk of making accidental outperformance decisions will become more serious as the firm knows more about its customers.

(5) Robust design to uncertainty: Once the retailer designs its optional after-sales service operations to be robust to an estimation error of customer preference, the risk of accidental outperformance will be undermined.

(6) Marketing-operations interface: There could be a case where the firm's operational efforts (i.e., efficient service offers) and the firm's marketing efforts (i.e., better understanding the customers) could be incompatible in the retailer's after-sales service operations.

Table 3 summarizes the first implication: a retailer plays a more important role than a manufacturer in achieving ideal outcomes in which a firm's profit maximization decision guarantees highest customer satisfaction. The second and third implications are derived from the discussion in Section 4. Note a twofold risk exists: the risk of a service decision discrepancy (i.e., 
the after-sales service level determined by profit maximization is less than the optimal level for customers) and the risk of overlooking such an erroneous discrepancy (e.g., what we call accidental outperformance, when a firm will not notice its mistake because the estimation error accidentally makes the firm's decision proximate to the customers' optimal level). The situation in which accidental outperformance may hide real problems is analogous to the famous depth-ofwater implication in JIT, where rocks on the sea bottom (i.e., real causes of problems) are unrecognized when the depth of water (i.e., inventory) is high enough to hide the rocks. The fourth implication obtained from Propositions 5 and 7 suggests that the likelihood of hiding erroneous decisions increases as the level of uncertainty decreases. The fifth implication, derived from the numerical example, suggests robust design to uncertainty as a method for coping with uncertainty. Finally, the sixth implication from the numerical example shows that the more efficiently a retailer offers an optional after-sales service to customers, the more likely accidental outperformance will occur. In sum, to deal with these issues, we emphasize that adequate coordination between marketing and operations departments is required to pursue profit and customer satisfaction simultaneously.

\section{Concluding remarks}

In this paper, we establish a two-stage supply chain model of after-sales service where two types of after-sales service - the base after-sales service offered by a manufacturer and the optional after-sales service offered by a retailer - are offered to two customer segments (the group using only basic after-sales service and the group purchasing an optional service plan). As an extension of Kurata and Nam's (2010) work, we explore how uncertainty in understanding customers' real needs for after-sales service can influence a firm's decisions on after-sales service offers. A key feature of the model is that a firm estimates its customers' optimum after-sales service level. To examine the role of asymmetric information in customers' optimal service levels, we formulate five different models. They find that, even in situations of uncertainty, the equilibrium after-sales service levels determined with a profit-maximization game in general differ from the optimal after-service level that customers prefer the most. We also propose the conditions that guarantee ideal situations where the equilibrium after-sales service level will be equivalent to the optimal level.

We present the possibility that the equilibrium after-sales service level of the uncertainty model will become closer to the optimal service level than that of the certainty model. We refer to this outcome as accidental outperformance. We investigate the probability that accidental outperformance occurs regarding service level and profit. We then propose counter-intuitive results that high accuracy of customer preference estimation and high efficiency in after-sales service operations will increase the chance that a firm will misunderstand the accidental outperformance and interpret it as a properly designed after-sales decision. Finally, based on the analytical findings, we develop several managerial insights regarding after-sales policies.

\section{Further Research.}

Unsolved questions in the current analysis remain. For example, we neglect any factors of obsolescence and short product life. The product lives of electronic appliances, such as flat-panel TV sets, cellular phones, and personal computers, are becoming shorter and shorter. Hence, including the effect of quick obsolescence and quick retail down pricing in the model would be an interesting extension of this after-sales service competition study. In addition, certain types of 
electric appliances and machines use a so-called Gillette model where a manufacturer gains revenue not by selling the appliances themselves but by selling the appliance's consumable parts and accessories as well as by offering after-sales services. For example, the printer and copier industry gains money by selling ink toner cartridges and/or by offering maintenance services to customers. Therefore, another direction for further research would combine after-sales competition in a supply chain with revenue-gaining sales of consumable parts and maintenance service plans. 


\section{References}

Aaker, D.A., Kumar, V., Day, G. D., 1998. Marketing Research Sixth edition. John Wiley \& Sons, New York:NY.

Amini, M.M., Retzlaff-Roberts, D., Bienstock, C.C., 2005. Designing a reverse logistics operations for short life cycle repair services. International Journal of Production Economics, 96 (3), 367-380.

Baker, T., Collier, D.A., 2005. The Economic Payout Model for Service Guarantee. Decision Sciences, 36 (2), 197-220.

Barmish, B.R., Lagoa, C.M., 1997. The Uniform Distribution: A Rigorous Justification for Its Use in Robustness Analysis. Mathematics of Control, Signals, and Systems, 10, 203-222.

Balachandran, K.R., Radhakrishnan, S., 2005. Quality Implications of Warranties in a Supply Chain. Management Science, 51 (8), 1266-1277.

Bensoussan, A., Sethi, S.P., 2007. The Machine Maintenance and Sale Age Model of Kamien and Schwartz Revisited. Management Science, 53 (12), 1964-1976.

Bernstein, F., Federgruen, A., 2004. A General Equilibrium Model for Industries with Price and Service Competition. Operations Research, 52(6), 868-886.

Bouguerra S., Chelbi A., Rezg N., 2012. A decision model for adopting an extended warranty under different maintenance policies. International Journal of Production Economics, $135,840-849$.

Chen, T., Kalra, A. Sun, B., 2010. Why Do Consumers Buy Extended Service Contracts? Journal of Consumer Research, 36, 611-623.

Chien, Y.H., 2005. Determining optimal warranty periods from the seller's perspective and optimal out-of-warranty replacement age from the buyer's perspective. International Journal of Systems Science, 36 (10), 631-637.

Chien, Y.H., 2012. The effects of a free-repair warranty on the discrete-time periodic replacement policy. International Journal of Production Economics, 135, 832-839.

Chu, J., Chintagunta, D. K., 2009. Quantifying the Economic Value of Warranties in the U.S. Server Market. Marketing Science, 28 (1), 99-121.

Chukova, S., Arnold, R., Wang, D.Q., 2004. Warranty analysis: An approach to modeling imperfect repairs. International Journal of Production Economics, 89 (1), 57-68.

Cohen, M.A., Agrawal, N., Agrawal, V., 2006. Winning in the aftermarket. Harvard Business Review, 84 (5), 129-138.

Cohen, M.A., Kunreuther, H., 2007. Operations Risk Management: Overview of Paul Kleindorfer's Contributions. Production and Operations Management, 6 (5), 525-541.

Corbett, C. J., 2001. Stochastic inventory systems in a supply chain with asymmetric information: Cycle stocks, safety stocks, and consignment stock. Operations Research 49 (4), 487-500.

Corbett, C.J., Zhou, D., and Tang, C.S., 2004. Designing Supply Contracts: Contract Type and Information Asymmetry. Management Science, 50 (4), 550-559.

Gupta, S., Lehmann, D.R., 2007. Managing Customers as Investments: The Strategic Value of Customers in the Long Run, Pearson Education as Wharton School Publishing, Upper Saddle Reviser: NJ.

Hanssens, D.M., Persons, L.J., Schultz, R.L., 2001. Market Response Models: Econometric and Time Series Analysis ( $2^{\text {nd }}$ ed.). Kluwer Academic Publishers, Boston: MA.

Hart, C. W. L., 1988. The Power of Unconditional Service Guarantee. Harvard Business Review, July-August, 54-62. 
Jack, N., Murthy D.N.P., 2006. A flexible extended warranty and related optimal strategies. Journal of the Operational Research Society, 58, 1612-1620.

Kurata, H., Nam, S., 2010. After-sales Service Competition in a Supply Chain: Optimization of Customer Satisfaction Level or Profit or Both? International Journal of Production Economics, 127 (1), 136-146.

Lau, A.H.L., Lau, H.S., 2005. Some two-echelon supply-chain games: Improving from deterministic-symmetric information to stochastic-asymmetric-information models. European Journal of Operational Research, 161, 203-223.

Leefland, P.S.H., Wittink, D.R., Wedel, M., and Naert, P.A., 2000. Building Models for Marketing Decisions. Kluwer Academic Publisher, Boston: MA.

Lin, P. C., Wang, J. Chin, S. S., 2009. Dynamic optimisation of price, warranty length and production rate. International Journal of System Science, 40 (4), 411-420.

Özer, Ö, Wei, W., 2006. Strategic Cmmitments for an Optimal Capacity Decision Uncer Asymmetric Forecast Information. Management Science, Vol. 52 (8), 1239-1258.

Simchi-Levi, D., Kaminsky, P., Simchi-Levi, E., 2008. Designing and Managing the Supply Chain: Concepts, Strategies and Case Studies ( $3^{\text {rd }}$ ed.). McGraw-Hill Irwin, Boston: MA.

Thonemann, U.W., Brown, A.O., Hausman, W.H., 2002. Easy Quantification of Improved Spare Parts Inventory Policies. Management Science, 48 (9), 1213-1225.

Tsay, A. A., Agrawal, N. 2000. Channel Dynamics Under Price and Service Competition. Manufacturing \& Service Operations Management, 2(4), 372-391.

White, S. W., 2013. An experimentally confirmed resource planning model of services under production function uncertainties. International Journal of Production Economics, 141, 478-484.

Wu, C. H., 2012. Price and service competition between new and remanufactured products in a two-echelon supply chain. International Journal of Production Economics, 140, 496507.

$\mathrm{Wu}, \mathrm{S}$., Longhurst P. 2011. Optimising age-replacement and extended non-reviewing warranty policies in lifecycle costing, International Journal of Production Economics, 130, 262267.

Xiao T., Yang, D. 2008. Price and service competition of supply chains with risk-averse retailers under demand uncertainty.International Journal of Production Economics, 114, 187200. 


\section{Appendix}

Proof of Proposition 1

FOC for (1), $\frac{\partial \pi_{R}^{1}(y \mid x)}{\partial y}=2 b_{1}(p+r-w)(\bar{x}+\bar{y}-x-y)-k_{R}+2 b_{1}(p+r-w)\left(\delta_{x}+\delta_{y}\right) \underset{\text { set }}{=0}$.

Then, $y^{*}=\bar{x}+\bar{y}-x-\frac{k_{R}}{2 b_{1}(p+r-w)}+\left(\delta_{x}+\delta_{y}\right)$.

FOC for (2), $\quad \frac{\partial \pi_{M}^{1}(x \mid y)}{\partial x}=2 b_{0}(w-c)(\bar{x}-x)+2 b_{1}(w-c)(\bar{x}+\bar{y}-x-y)-k_{M}+2 b_{0}(w-$ c) $\delta_{x}+2 b_{1}(w-c)\left(\delta_{x}+\delta_{y}\right) \underset{\text { set }}{=}$.

Then, $x^{*}=\bar{x}+\frac{b_{1}}{b_{0}+b_{1}}(\bar{y}-y)-\frac{k_{M}}{2\left(b_{0}+b_{1}\right)(w-c)}+\delta_{x}+\frac{b_{1}}{b_{0}+b_{1}} \delta_{y}$.

Solving (A.1) and (A.2) simultaneously results in the Nash solution. Then, the equilibrium is expressed as the following matrix form:

$\left[\begin{array}{cc}1 & 1 \\ 1 & b_{1} /\left(b_{0}+b_{1}\right)\end{array}\right]\left[\begin{array}{l}x^{1^{*}} \\ y^{1^{*}}\end{array}\right]=\left[\begin{array}{c}\bar{x}+\bar{y}+\delta_{x}+\delta_{y}-k_{R} / 2 b_{1}(p+r-w) \\ \bar{x}+b_{1} \bar{y} /\left(b_{0}+b_{1}\right)+\delta_{x}+b_{1} \delta_{y} /\left(b_{0}+b_{1}\right)-k_{M} / 2\left(b_{0}+b_{1}\right)(w-c)\end{array}\right]$

Let $\left[\begin{array}{cc}1 & 1 \\ 1 & b_{1} /\left(b_{0}+b_{1}\right)\end{array}\right]=A$. Note that $\operatorname{det}[A]=\frac{b_{1}}{b_{0}+b_{1}}-1=\frac{-b_{0}}{b_{0}+b_{1}}<0$ from the assumption. Thus, $A$

has an inverse matrix with $A^{-1}=\frac{1}{b_{0}}\left[\begin{array}{cc}-b_{0} & \left(b_{0}+b_{1}\right) \\ \left(b_{0}+b_{1}\right) & -\left(b_{0}+b_{1}\right)\end{array}\right]$.

Thus, $\left[\begin{array}{l}x^{1 *} \\ y^{1 *}\end{array}\right]=\frac{1}{b_{0}}\left[\begin{array}{cc}-b_{0} & \left(b_{0}+b_{1}\right) \\ \left(b_{0}+b_{1}\right) & -\left(b_{0}+b_{1}\right)\end{array}\right] \times$

$$
\begin{gathered}
{\left[\begin{array}{c}
\bar{x}+\bar{y}+\delta_{x}+\delta_{y}-k_{R} / 2 b_{1}(p+r-w) \\
\bar{x}+b_{1} \bar{y} /\left(b_{0}+b_{1}\right)+\delta_{x}+b_{1} \delta_{y} /\left(b_{0}+b_{1}\right)-k_{M} / 2\left(b_{0}+b_{1}\right)(w-c)
\end{array}\right]} \\
=\left[\begin{array}{c}
\bar{x}+\delta_{x}+k_{R} / 2 b_{0}(p+r-w)-k_{M} / 2 b_{0}(w-c) \\
\bar{y}+\delta_{y}-k_{R}\left(b_{0}+b_{1}\right) / 2 b_{0} b_{1}(p+r-w)+k_{M} / 2 b_{0}(w-c)
\end{array}\right] .
\end{gathered}
$$

(b) From (A.3), to achieve $x^{1 *}=\bar{x}$ and $y^{1 *}=\bar{y}$ requires $\delta_{x}=-\frac{k_{R}}{2 b_{0}(p+r-w)}+\frac{k_{M}}{2 b_{0}(w-c)}$ and $\delta_{y}=$ $\frac{\left(b_{0}+b_{1}\right) k_{R}}{2 b_{0} b_{1}(p+r-w)}-\frac{k_{M}}{2 b_{0}(w-c)}$.

(c) From (A.3), to achieve $x^{1 *}+y^{1 *}=\bar{x}+\bar{y}$ requires $\delta_{x}+\delta_{y}-\frac{k_{R}}{2 b_{1}(p+r-w)}=0$.

\section{Proof of Proposition 2.}

(a) Case 2 assumes that no error exists in the estimation of $\bar{x}$. Thus, the profit functions for Case 2 are defined as follows:

For a retailer, $\pi_{R}^{2}(y \mid x)=(p-w)\left\{a_{0}+b_{0} x(2 \bar{x}-x)\right\}+(p+r-w)\left\{a_{1}+b_{1}(x+y)(2 \bar{x}+2 \bar{y}-x-y)\right\}$

$$
-k_{R} y+2 b_{1}(p+r-w)(x+y) \delta_{y}, \text { and }
$$

for a manufacturer,

$$
\begin{aligned}
& \pi_{M}^{1}(x \mid y)=(w-c)\left\{a_{0}+b_{0} x(2 \bar{x}-x)+a_{1}+b_{1}(x+y)(2 \bar{x}+2 \bar{y}-x-y)\right\} \\
& -k_{M} x+2 b_{1}(w-c)(x+y) \delta_{y} .
\end{aligned}
$$

Thus, $\frac{\partial \pi_{M}^{2}}{\partial x}=(w-c)\left\{2 b_{0}(\bar{x}-x)+2 b_{1}(\bar{x}+\bar{y}-x-y)\right\}-k_{M}+2 b_{1}(w-c) \delta_{y}$, and 
$\frac{\partial \pi_{R}^{2}}{\partial y}=(p+r-w)\left\{2 b_{1}(\bar{x}+\bar{y}-x-y)\right\}-k_{R}+2 b_{1}(p+r-w) \delta_{y}$.

Solving simultaneously $\frac{\partial \pi_{M}^{2}}{\partial x}=0$ and $\frac{\partial \pi_{R}^{2}}{\partial y}=0$, we obtain,

$\left[\begin{array}{l}x^{2 *} \\ y^{2 *}\end{array}\right]=\left[\begin{array}{c}\bar{x}+\frac{k_{R}}{2 b_{0}(p+r-w)}-\frac{k_{M}}{2 b_{0}(w-c)} \\ \bar{y}-\frac{\left(b_{0}+b_{1}\right) k_{R}}{2 b_{0} b_{1}(p+r-w)}+\frac{k_{M}}{2 b_{0}(w-c)}+\delta_{y}\end{array}\right]$.

(b) and (c). It is easy to derive the conditions for Ideal Types 1 and 2 from (A.4).

\section{Proof of Proposition 3.}

(a) Case 3 assumes that a retailer knows the information of both $\bar{x}$ and $\bar{y}$ while a manufacturer knows neither. Hence, the profit functions for Case 3 are defined as follows:

For a retailer, $\pi_{R}^{3}(y \mid x)=(p-w)\left\{a_{0}+b_{0} x(2 \bar{x}-x)\right\}+(p+r-w)\left\{a_{1}+b_{1}(x+y)(2 \bar{x}+2 \bar{y}-x-y)\right\}$ $-k_{R} y$, and

for a manufacturer,

$$
\begin{aligned}
& \pi_{M}^{3}(x \mid y)=(w-c)\left\{a_{0}+b_{0} x(2 \bar{x}-x)+a_{1}+b_{1}(x+y)(2 \bar{x}+2 \bar{y}-x-y)\right\}-k_{M} x . \\
& +\left\{2 b_{0}(w-c) x+2 b_{1}(w-c)(x+y)\right\} \delta_{x}+2 b_{1}(w-c)(x+y) \delta_{y} .
\end{aligned}
$$

Thus, $\frac{\partial \pi_{M}^{3}}{\partial x}=(w-c)\left\{2 b_{0}(\bar{x}-x)+2 b_{1}(\bar{x}+\bar{y}-x-y)\right\}-k_{M}$

$$
+2\left(b_{0}+b_{1}\right)(w-c) \delta_{x}+2 b_{1}(w-c) \delta_{y}, \text { and }
$$

$\frac{\partial \pi_{R}^{3}}{\partial y}=(p+r-w)\left\{2 b_{1}(\bar{x}+\bar{y}-x-y)\right\}-k_{R}$.

Solving simultaneously $\frac{\partial \pi_{M}^{3}}{\partial x}=0$ and $\frac{\partial \pi_{R}^{3}}{\partial y}=0$ results in,

$$
\left[\begin{array}{l}
x^{3 *} \\
y^{3 *}
\end{array}\right]=\left[\begin{array}{c}
\bar{x}+\frac{k_{R}}{2 b_{0}(p+r-w)}-\frac{k_{M}}{2 b_{0}(w-c)}+\frac{b_{0}+b_{1}}{b_{0}} \delta_{x}+\frac{b_{1}}{b_{0}} \delta_{y} \\
\bar{y}-\frac{\left(b_{0}+b_{1}\right) k_{R}}{2 b_{0} b_{1}(p+r-w)}+\frac{k_{M}}{2 b_{0}(w-c)}-\frac{b_{0}+b_{1}}{b_{0}} \delta_{x}-\frac{b_{1}}{b_{0}} \delta_{y}
\end{array}\right] .
$$

(b)From (A.5), it is necessary for achieving Ideal Type 1 to satisfy

$$
\begin{gathered}
\frac{k_{R}}{2 b_{0}(p+r-w)}-\frac{k_{M}}{2 b_{0}(w-c)}+\frac{b_{0}+b_{1}}{b_{0}} \delta_{x}+\frac{b_{1}}{b_{0}} \delta_{y}=0, \text { and } \\
-\frac{\left(b_{0}+b_{1}\right) k_{R}}{2 b_{0} b_{1}(p+r-w)}+\frac{k_{M}}{2 b_{0}(w-c)}-\frac{b_{0}+b_{1}}{b_{0}} \delta_{x}-\frac{b_{1}}{b_{0}} \delta_{y}=0 .
\end{gathered}
$$

This can be simplified as $\frac{k_{R}}{2 b_{0}(p+r-w)}=\frac{\left(b_{0}+b_{1}\right) k_{R}}{2 b_{0} b_{1}(p+r-w)}$. Equivalently, $\frac{b_{0}+b_{1}}{b_{1}}=1$. This requires $b_{0}=0$ but our assumption is $b_{0}>0$. As a result, Ideal Type 1 is impossible for Case 3 .

(c) From (A.5), it is necessary for achieving Ideal Type 2 to satisfy $\frac{k_{R}}{2 b_{0}(p+r-w)}-$ $\frac{\left(b_{0}+b_{1}\right) k_{R}}{2 b_{0} b_{1}(p+r-w)}=0$. This is equivalent to $\frac{k_{R}}{2 b_{1}(p+r-w)}=0$. However, $\frac{k_{R}}{2 b_{1}(p+r-w)}=0$ is impossible from the assumption $k_{R}>0$. Hence, $x^{3 *}+y^{3 *}=\bar{x}+\bar{y}-\frac{-b_{0} k_{R}}{2 b_{0}(p+r-w)}<\bar{x}+\bar{y}$.

(d) Case 4 assumes that a retailer knows the information of both $\bar{x}$ and $\bar{y}$ while a manufacturer knows only $\bar{x}$. Hence, the profit functions for Case 4 are defined as follows:

For a retailer, $\pi_{R}^{4}(y \mid x)=(p-w)\left\{a_{0}+b_{0} x(2 \bar{x}-x)\right\}+(p+r-w)\left\{a_{1}+b_{1}(x+y)(2 \bar{x}+2 \bar{y}-x-y)\right\}$

$$
-k_{R} y
$$

and for a manufacturer,

$$
\pi_{M}^{4}(x \mid y)=(w-c)\left\{a_{0}+b_{0} x(2 \bar{x}-x)+a_{1}+b_{1}(x+y)(2 \bar{x}+2 \bar{y}-x-y)\right\}
$$




$$
-k_{M} x+2 b_{1}(w-c)(x+y) \delta_{y} .
$$

Thus, $\frac{\partial \pi_{M}^{4}}{\partial x}=(w-c)\left\{2 b_{0}(\bar{x}-x)+2 b_{1}(\bar{x}+\bar{y}-x-y)\right\}-k_{M}+2 b_{1}(w-c) \delta_{y}$, and

$\frac{\partial \pi_{R}^{4}}{\partial y}=(p+r-w)\left\{2 b_{1}(\bar{x}+\bar{y}-x-y)\right\}-k_{R}$.

Solving simultaneously $\frac{\partial \pi_{M}^{4}}{\partial x}=0$ and $\frac{\partial \pi_{R}^{4}}{\partial y}=0$ results in,

$\left[\begin{array}{c}x^{4 *} \\ y^{4 *}\end{array}\right]=\left[\begin{array}{c}\bar{x}+\frac{k_{R}}{2 b_{0}(p+r-w)}-\frac{k_{M}}{2 b_{0}(w-c)}+\frac{b_{1}}{b_{0}} \delta_{y} \\ \bar{y}-\frac{\left(b_{0}+b_{1}\right) k_{R}}{2 b_{0} b_{1}(p+r-w)}+\frac{k_{M}}{2 b_{0}(w-c)}-\frac{b_{1}}{b_{0}} \delta_{y}\end{array}\right]$.

From (A.6), it is necessary for achieving Ideal Type 1 to satisfy,

$$
\frac{k_{R}}{2 b_{0}(p+r-w)}-\frac{k_{M}}{2 b_{0}(w-c)}+\frac{b_{1}}{b_{0}} \delta_{y}=0 \text { and }-\frac{\left(b_{0}+b_{1}\right) k_{R}}{2 b_{0} b_{1}(p+r-w)}+\frac{k_{M}}{2 b_{0}(w-c)}-\frac{b_{1}}{b_{0}} \delta_{y}=0 .
$$

However, the impossibility of achieving Ideal Type 1 for Case 4 can be proved by the same logic as the proof of Proposition 3 (b). Also for Ideal Type 2, from (A.6) $x^{4 *}+y^{4 *}=\bar{x}+\bar{y}$

$-\frac{k_{R}}{2 b_{1}(p+r-w)}<\bar{x}+\bar{y}$ due to $k_{R}>0$. Hence, it is impossible to achieve Ideal Type 2 for Case 4 , either.

\section{Proof of Proposition 4.}

Case 5 assumes that a retailer knows only $\bar{y}$ while a manufacturer knows only $\bar{x}$. Hence, the profit functions for Case 3 are defined as follows:

For a retailer, $\pi_{R}^{5}(y \mid x)=(p-w)\left\{a_{0}+b_{0} x(2 \bar{x}-x)\right\}+(p+r-w)\left\{a_{1}+b_{1}(x+y)(2 \bar{x}+2 \bar{y}-x-y)\right\}$

$$
-k_{R} y+\left\{2 b_{0}(p-w) x+2 b_{1}(p+r-w)(x+y)\right\} \delta_{x}, \text { and }
$$

for a manufacturer,

$$
\begin{aligned}
& \pi_{M}^{5}(x \mid y)=(w-c)\left\{a_{0}+b_{0} x(2 \bar{x}-x)+a_{1}+b_{1}(x+y)(2 \bar{x}+2 \bar{y}-x-y)\right\}-k_{M} x \\
& +2 b_{1}(w-c)(x+y) \delta_{y} .
\end{aligned}
$$

Thus, $\frac{\partial \pi_{M}^{5}}{\partial x}=(w-c)\left\{2 b_{0}(\bar{x}-x)+2 b_{1}(\bar{x}+\bar{y}-x-y)\right\}-k_{M}+2 b_{1}(w-c) \delta_{y}$, and

$\frac{\partial \pi_{R}^{5}}{\partial y}=2 b_{1}(p+r-w)(\bar{x}+\bar{y}-x-y)-k_{R}+2 b_{1}(p+r-w) \delta_{x}$.

Solving simultaneously $\frac{\partial \pi_{M}^{5}}{\partial x}=0$ and $\frac{\partial \pi_{R}^{5}}{\partial y}=0$ results in,

$\left[\begin{array}{l}x^{5 *} \\ y^{5 *}\end{array}\right]=\left[\begin{array}{c}\bar{x}+\frac{k_{R}}{2 b_{0}(p+r-w)}-\frac{k_{M}}{2 b_{0}(w-c)}-\frac{b_{1}}{b_{0}} \delta_{x}+\frac{b_{1}}{b_{0}} \delta_{y} \\ \bar{y}-\frac{\left(b_{0}+b_{1}\right) k_{R}}{2 b_{0} b_{1}(p+r-w)}+\frac{k_{M}}{2 b_{0}(w-c)}+\frac{b_{0}+b_{1}}{b_{0}} \delta_{x}-\frac{b_{1}}{b_{0}} \delta_{y}\end{array}\right]$.

Next, from (A.7) it is necessary for achieving Ideal Type 1 to satisfy simultaneously

$\frac{k_{R}}{2 b_{0}(p+r-w)}-\frac{k_{M}}{2 b_{0}(w-c)}+\frac{b_{1}}{b_{0}} \delta_{x}+\frac{b_{1}}{b_{0}} \delta_{y}=0$ and $-\frac{\left(b_{0}+b_{1}\right) k_{R}}{2 b_{0} b_{1}(p+r-w)}+\frac{k_{M}}{2 b_{0}(w-c)}+\frac{b_{0}+b_{1}}{b_{0}} \delta_{x}-\frac{b_{1}}{b_{0}} \delta_{y}=0$.

This can be rewritten as $\delta_{x}=\frac{k_{R}}{2 b_{1}(p+r-w)}$ and $\delta_{y}=\frac{k_{M}}{2 b_{1}(w-c)}$.

Also, we know from (A.7) that achieving Ideal Type 2 requires $\frac{k_{R}}{2 b_{0}(p+r-w)}-\frac{k_{M}}{2 b_{0}(w-c)}-\frac{b_{1}}{b_{0}} \delta_{x}+$ $\frac{b_{1}}{b_{0}} \delta_{y}-\frac{\left(b_{0}+b_{1}\right) k_{R}}{2 b_{0} b_{1}(p+r-w)}+\frac{k_{M}}{2 b_{0}(w-c)}+\delta_{x}+\frac{b_{1}}{b_{0}} \delta_{x}-\frac{b_{1}}{b_{0}} \delta_{y}=0$. This can be simplifed as $\delta_{x}=$ $\frac{k_{R}}{2 b_{1}(p+r-w)}$.

\section{Proof of Proposition 5.}


As Section 4 explains, the probability that accidental outperformance occurs is determined by the ratio of the area that satisfies Condition (19), Equation (22), and Equation (23) to the area of the feasible region of the estimation-realization gaps $\delta_{x}$ and $\delta_{y}$ (i.e., the area determined by Condition (19)). However, according to parameter values, there exist several occasions where Equations (22) and (23) cross over the borders of the feasible region of $\delta_{x}$ and $\delta_{y}$. Then, the probability should be calculated for each occasion.

First, we consider the case of $\varepsilon_{x} \geq \varepsilon_{y}$. Equation (22), which is illustrated by Line B-B' in Figure 4, intersects the feasible region determined by $\varepsilon_{x}$ and $\varepsilon_{y}$ (i.e., the meshed area in Figure 4) on three occasions: (i) Equation (22) is located outside of the feasible region (i.e., the case represented by Line $B_{1}-B_{1}$ ' in Figure 7); (ii) Equation (22) intersects at edge $S_{1}-S_{4}$ of the feasible region (i.e., the case represented by Line $\mathrm{B}_{2}-\mathrm{B}_{2}$ ' in Figure 7); and (iii) Equation (19) intersects at edge $S_{3}-S_{4}$ of the feasible region (i.e., the case represented by Line $B_{3}-B_{3}$ ' in Figure 7 ). For each occasion, it is not difficult to calculate the ratio of the area where accidental outperformance occurs to the area of the feasible region. Consequently, the probabilities of Proposition 5 (1-a), (1-b), and (1-c) are determined.

Next, we consider the case of $\varepsilon_{x}<\varepsilon_{y}$. In this case, there are also three occasions where Line B-B' intersects the feasible region determined by $\varepsilon_{x}$ and $\varepsilon_{y}$. The probability can be calculated by the same approach as the case of $\varepsilon_{x} \geq \varepsilon_{y}$. As a result, Proposition 5 (2-a), (2-b), and (2-c) are determined.

\section{(Insert Figure 7 around here)}

\section{Proof of Proposition 6.}

It is easy to show $\frac{\partial \pi_{R}^{1}}{\partial \delta_{x}}>0, \frac{\partial \pi_{R}^{1}}{\partial \delta_{y}}>0, \frac{\partial \pi_{M}^{1}}{\partial \delta_{x}}>0$, and $\frac{\partial \pi_{M}^{1}}{\partial \delta_{y}}>0$ from (5) and (6).

The total differentiation of $\pi_{R}^{1}+\pi_{M}^{1}$ is,

$d\left(\pi_{R}^{1}+\pi_{M}^{1}\right)=\frac{\partial\left(\pi_{R}^{1}+\pi_{M}^{1}\right)}{\partial \delta_{x}} d \delta_{x}+\frac{\partial\left(\pi_{R}^{1}+\pi_{M}^{1}\right)}{\partial \delta_{y}} d \delta_{y}$.

Since $\frac{\partial\left(\pi_{R}^{1}+\pi_{M}^{1}\right)}{\partial \delta_{x}}>0$ and $\frac{\partial\left(\pi_{R}^{1}+\pi_{M}^{1}\right)}{\partial \delta_{y}}>0$, then $d\left(\pi_{R}^{1}+\pi_{M}^{1}\right)>0$ if $\frac{d \delta_{y}}{d \delta_{x}}>-\frac{\partial\left(\pi_{R}^{1}+\pi_{M}^{1}\right) / \partial \delta_{x}}{\partial\left(\pi_{R}^{1}+\pi_{M}^{1}\right) / \partial \delta_{y}}$ from (A.8).

As a result, if the estimation-realization gaps $\delta_{x}$ and $\delta_{y}$ are located over the following equation

$\delta_{y}=-\frac{\partial\left(\pi_{R}^{1}+\pi_{M}^{1}\right) / \partial \delta_{x}}{\partial\left(\pi_{R}^{1}+\pi_{M}^{1}\right) / \partial \delta_{y}} \delta_{x}$

the total profit of the uncertainty model, $\pi_{R}^{1}+\pi_{M}^{1}$, will be more than that of the certainty model that is achieved when $\delta_{x}=\delta_{y}=0$. Due to the symmetric structure of the feasible region of $\varepsilon_{x}$ and $\varepsilon_{y}$ and (A.9), the probability that the total profit of the uncertainty model overcomes that of the certainty model can be determined as 0.5 .

\section{Proof of Proposition 7.}

Also, from (5) and (6),

$$
\begin{aligned}
& \frac{\partial\left(\pi_{R}^{1}+\pi_{M}^{1}\right)}{\partial \delta_{x}}=2 b_{0}(p-w) x+2 b_{1}(p+r-w)(x+y)+2 b_{0}(w-c) x \\
& +2 b_{1}(w-c)(x+y), \text { and } \\
& \frac{\partial\left(\pi_{R}^{1}+\pi_{M}^{1}\right)}{\partial \delta_{y}}=2 b_{1}(p+r-w)(x+y)+2 b_{1}(w-c)(x+y) .
\end{aligned}
$$


Thus, from (A10) and (A11), $\frac{\partial\left(\pi_{R}^{1}+\pi_{M}^{1}\right)}{\partial \delta_{x}}>\frac{\partial\left(\pi_{R}^{1}+\pi_{M}^{1}\right)}{\partial \delta_{y}}$. Therefore, $\frac{\partial\left(\pi_{R}^{1}+\pi_{M}^{1}\right) / \partial \delta_{x}}{\partial\left(\pi_{R}^{1}+\pi_{M}^{1}\right) / \partial \delta_{y}}>1$.

\section{(Insert Figure 8 around here)}

Consequently, the slope of Equation (A.9) is steeper than that of Equation (18) with the slope of -1. Thus, Equation (A.9) can be illustrated by Line D-D' in Figure 8. The probability that accidental outperformance of both service level and total profit occurs is defined by the ratio of the area defined by Condition (19), Equations (22), (23), and (A.9) (i.e. the shaded area in Figure $8)$ to the area of the feasible region of $\varepsilon_{x}$ and $\varepsilon_{y}$.

When $\varepsilon_{x} \geq \varepsilon_{y}$, there are four occasions where Equations (18) and (A.9) are positioned over the feasible region of $\varepsilon_{x}$ and $\varepsilon_{y}$. Calculating the probability for each occasion results in Proposition 7 (1-a), (1-b), (1-c), and (1-d). Also, when $\varepsilon_{x}<\varepsilon_{y}$, there are six occasions where Equations (18) and (A.9) intersect the feasible region. Calculating the probability for each classification results in Proposition 7 (2-a) through (2-f). 


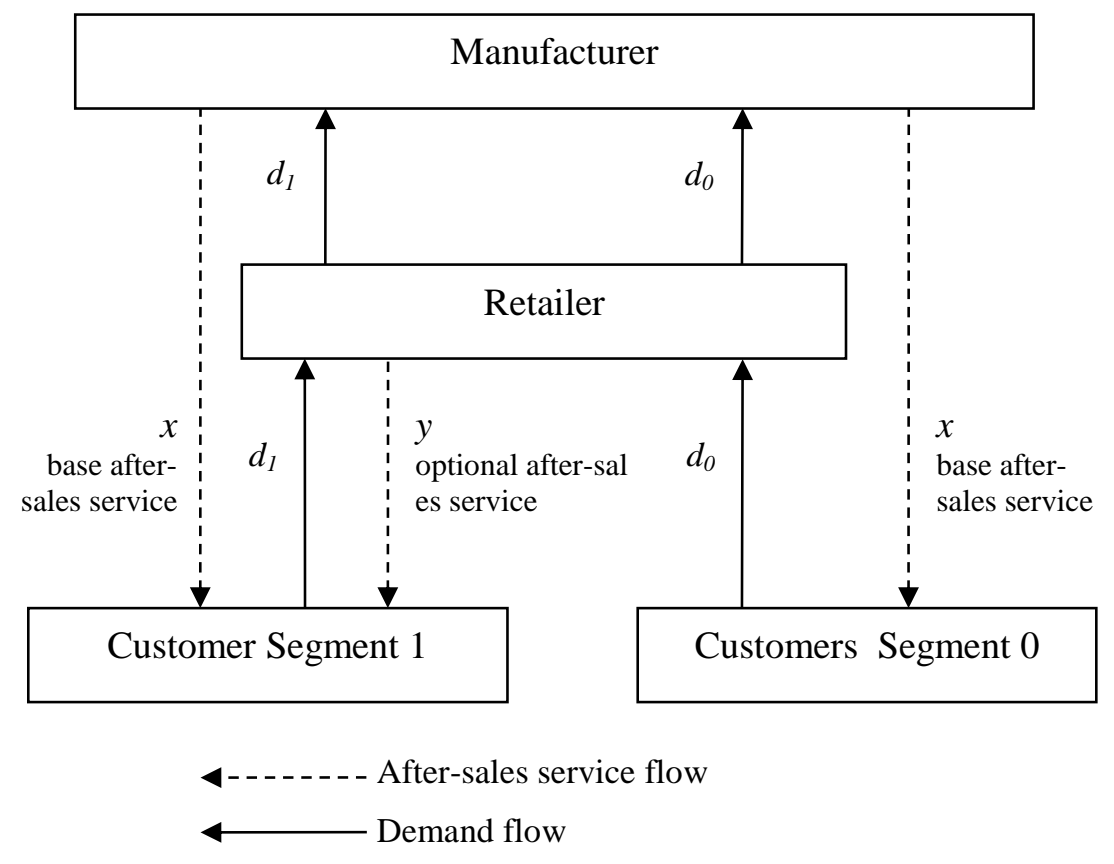

Fig. 1. Supply Chain Structure 


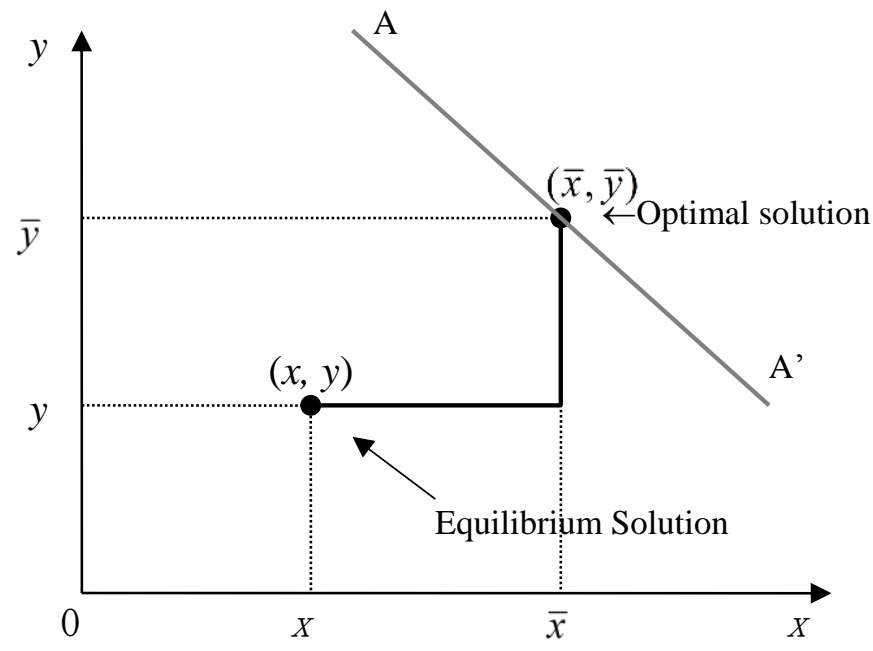

Fig. 2. Service Quality Measurement 
1. A firm (e.g., manufacturer) estimates the optimal level

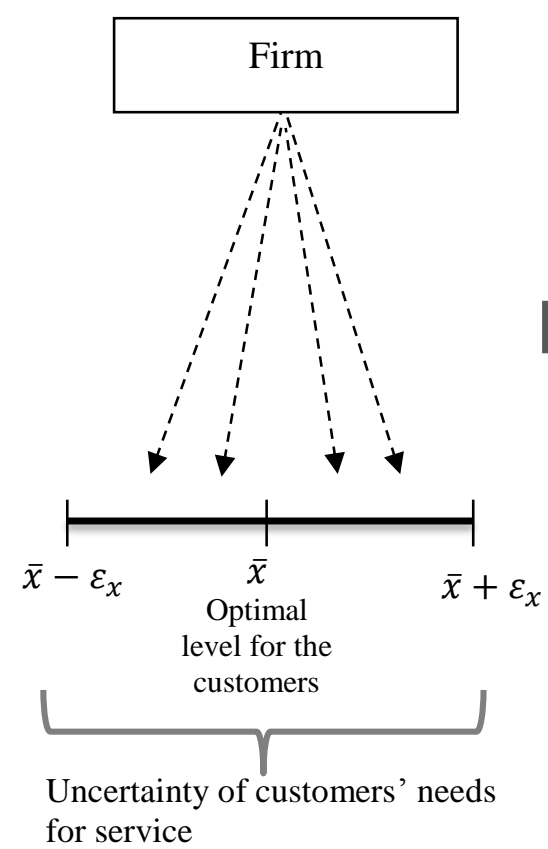

2 The firm decides an after-sales service $\left(x^{*}\right)$ based on the estimation $(\hat{x})$.

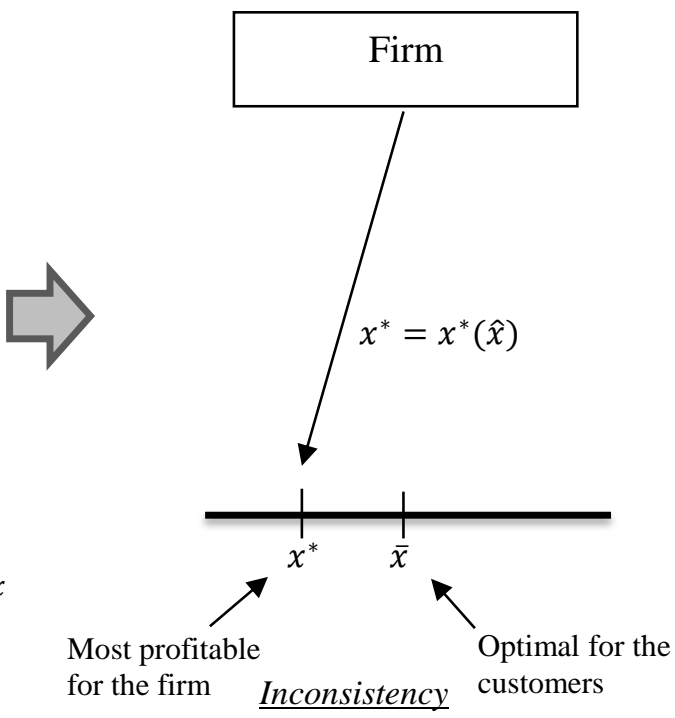

Fig. 3. Procedure for an After-sales Service Decision under Uncertainty 


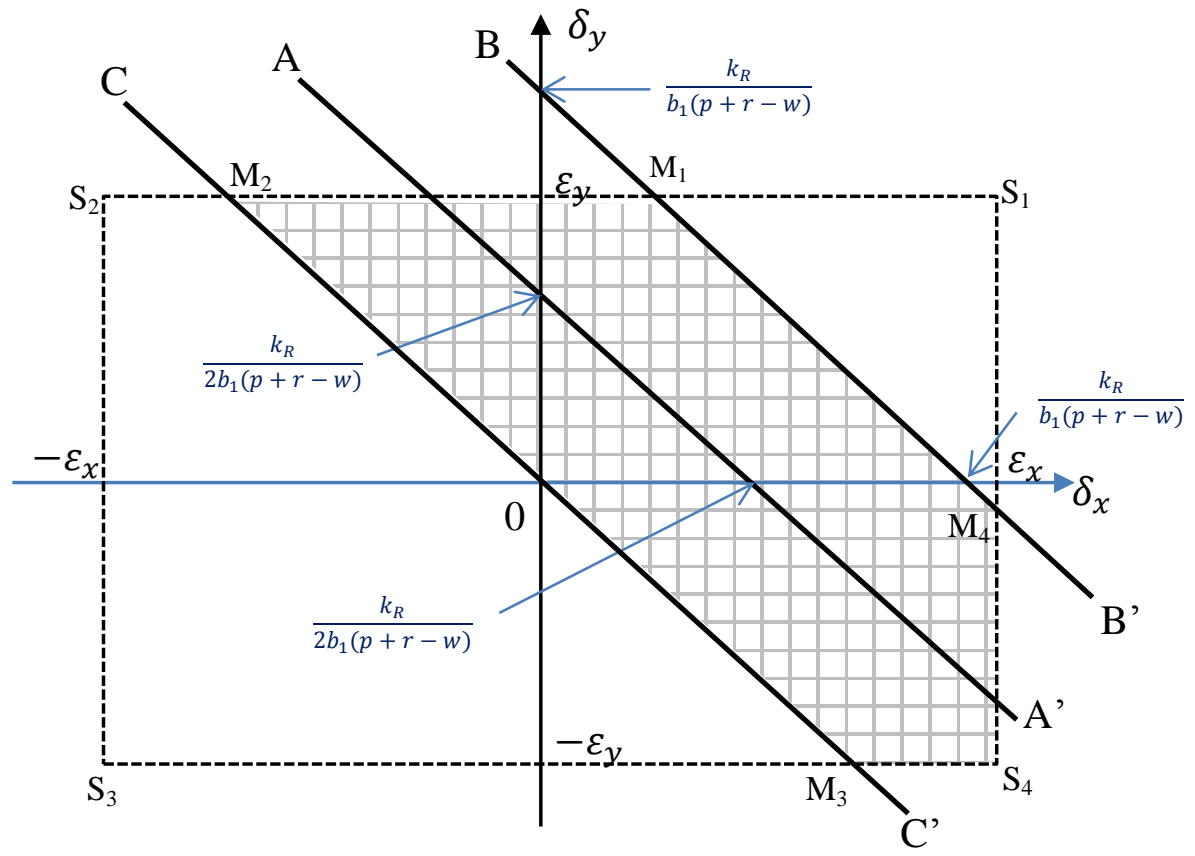

Fig. 4. Condition for Ideal Type 2 for Case 1 


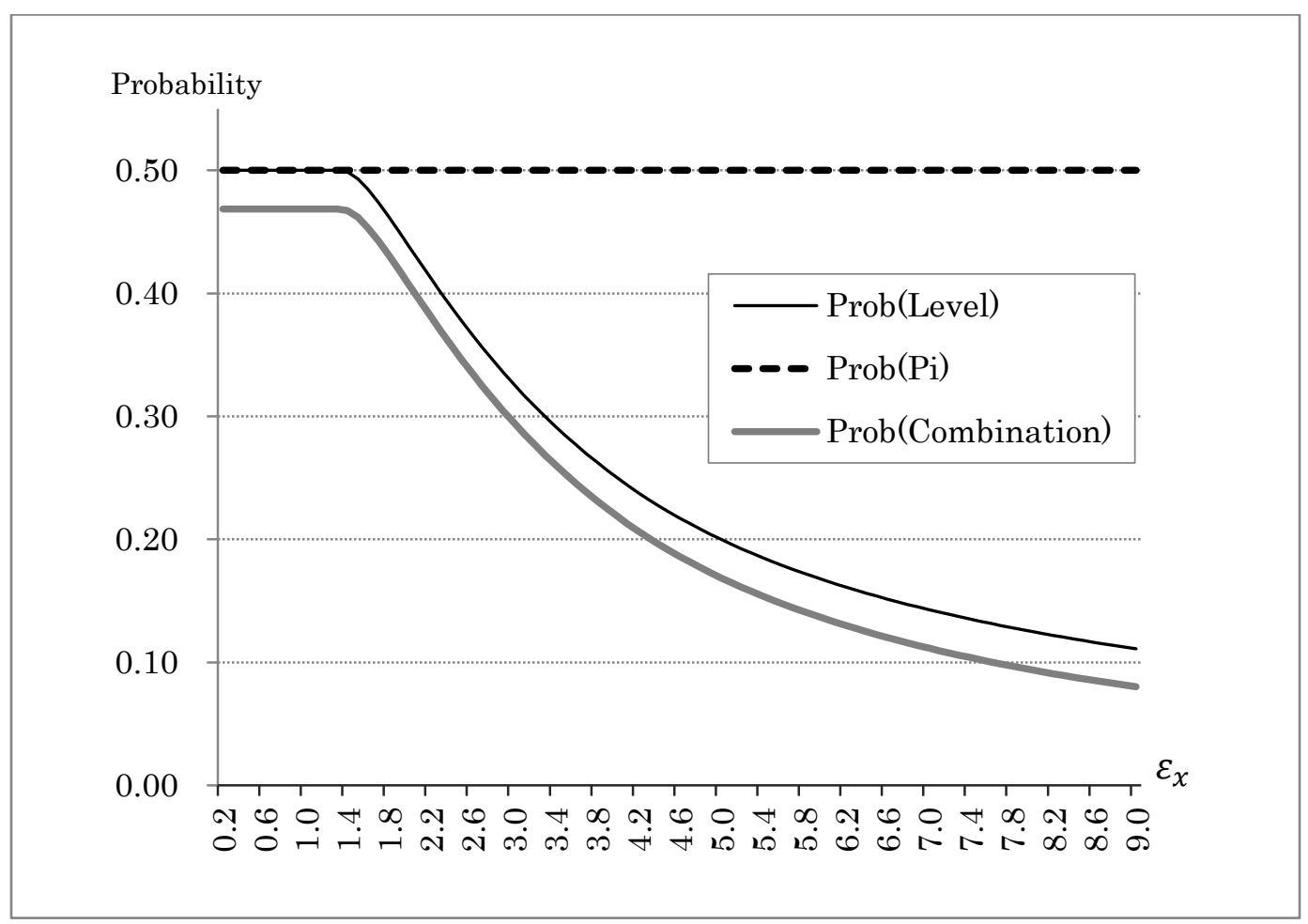

Fig. 5. Effect of $\varepsilon_{x}$ and $\varepsilon_{y}$ on the Probabilities of Over-estimation 


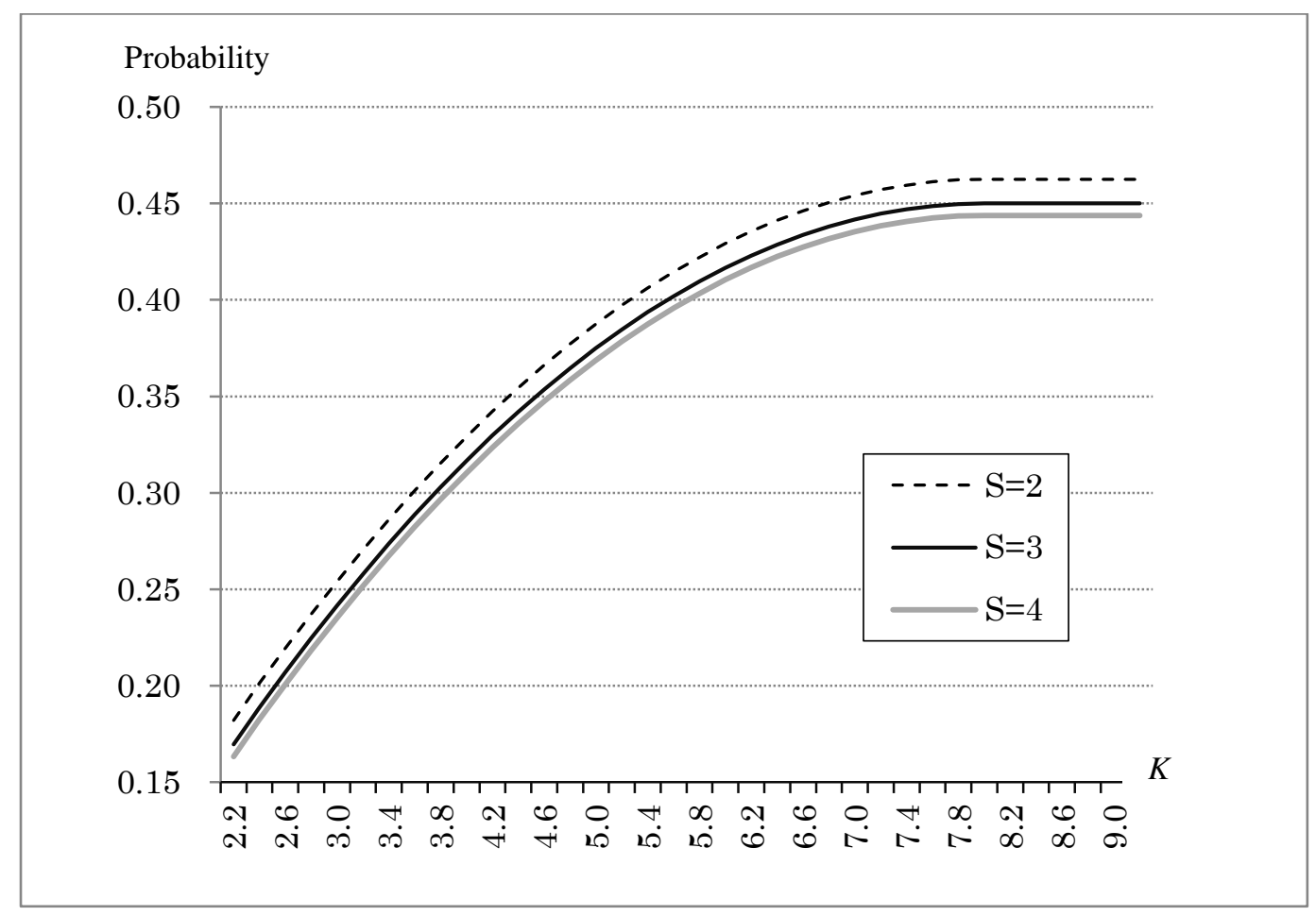

Fig. 6. Effect of $K$ and $S$ on the Probabilities of Over-estimation 


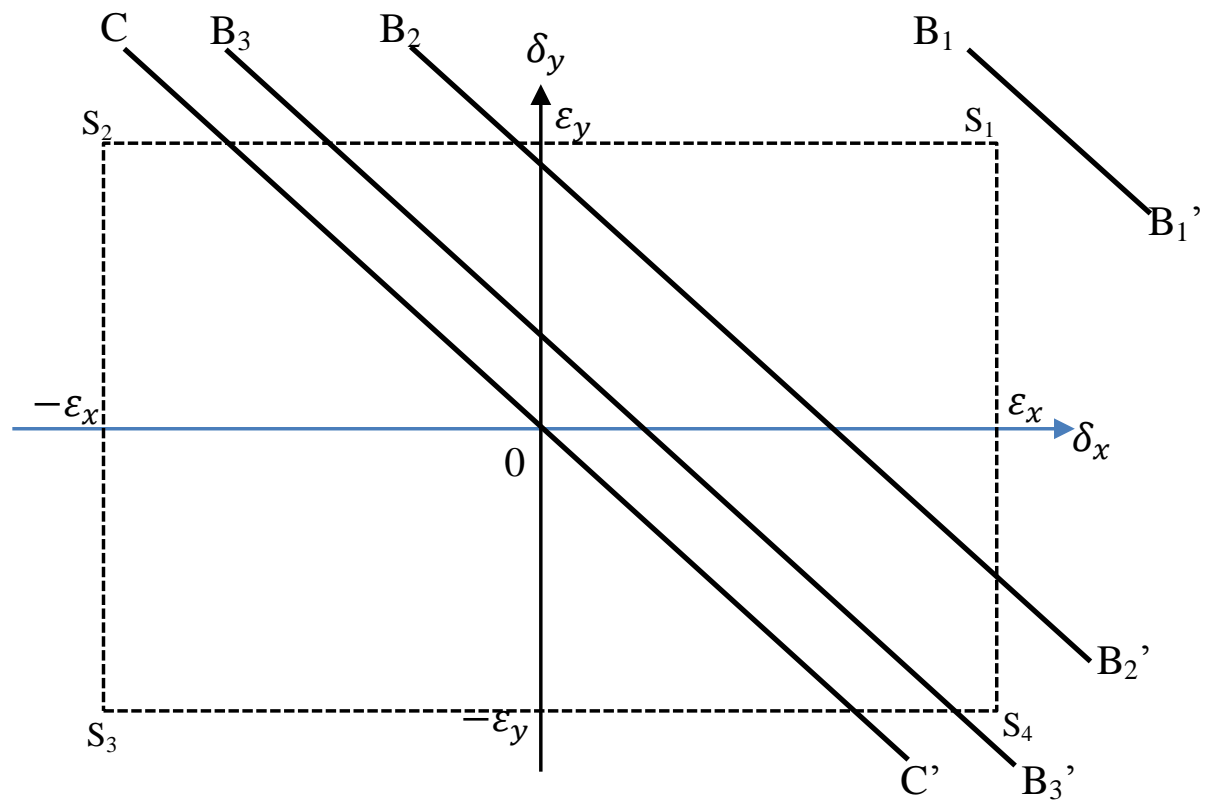

Fig. 7. Three classifications of the line B-B' 


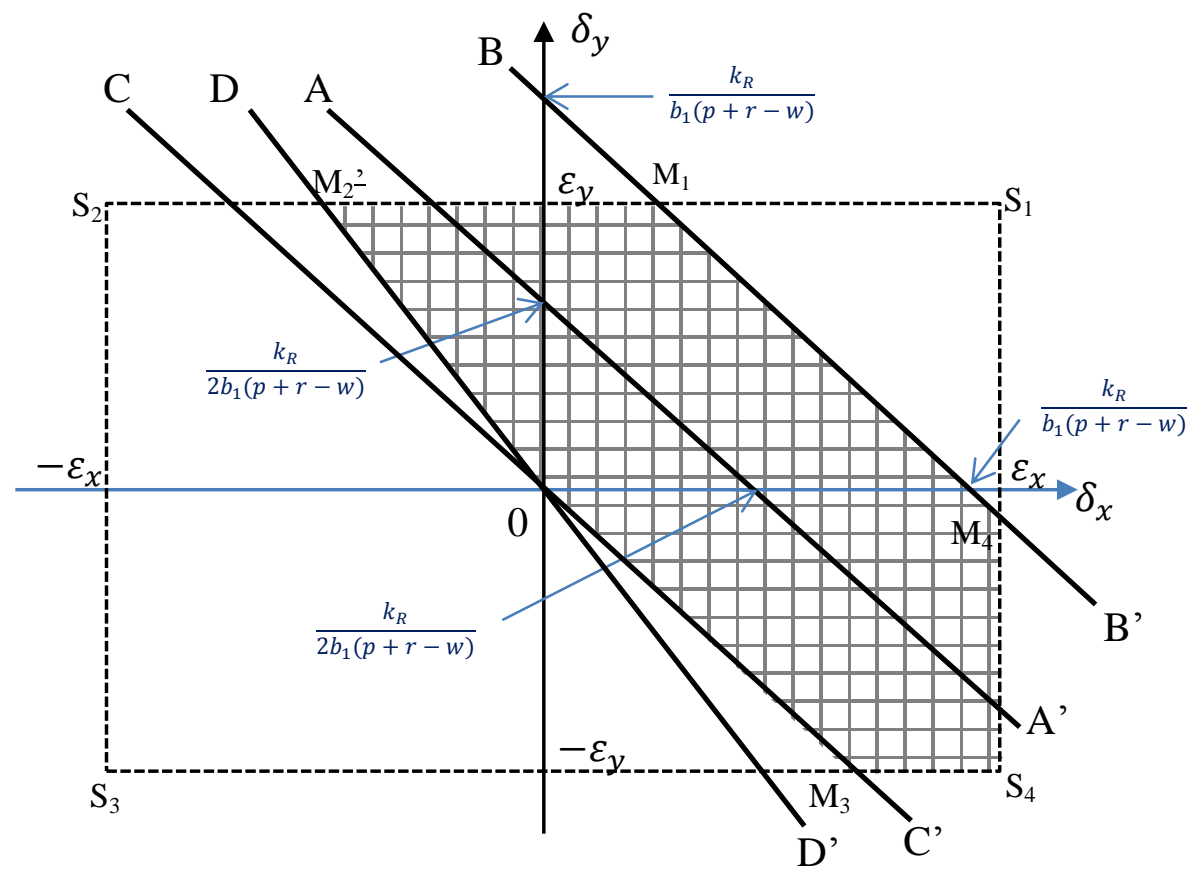

Fig.8. The region where both the total after-sales service level and the total profit under uncertainty overcomes those under certainty. 
Table 1. Symbols and Subscripts

\begin{tabular}{|c|c|}
\hline symbols & \\
\hline$x$ & basic after-sales service level determined by a manufacturer \\
\hline $\mathrm{y}$ & optional after-sales service level determined by a retailer \\
\hline $\bar{x}$ & optimal after-sales service level for a manufacturer $(\bar{x}>1)$ \\
\hline $\bar{y}$ & optimal after-sales service level for a retailer $(\bar{y}>1)$ \\
\hline$\hat{x}$ and $\hat{y}$ & estimation of $\bar{x}$ and $\bar{y}$, respectively \\
\hline$\varepsilon_{x}$ and $\varepsilon_{x}$ & half ranges of uniform distribution for $\hat{x}$ and $\hat{y}$, respectively \\
\hline$\delta_{x}$ and $\delta_{y}$ & estimation error for $\bar{x}$ and $\bar{y}$ where $\hat{x}=\bar{x}+\delta_{x}$ and $\hat{y}=\bar{y}+\delta_{y}$. \\
\hline$d_{0}$ & Segment 0 demand \\
\hline$d_{1}$ & Segment 1 demand \\
\hline$\pi_{M}(x \mid y)$ & manufacturer's profit \\
\hline$\pi_{R}(y \mid x)$ & retailer's profit \\
\hline$k_{M}$ & coefficient for manufacturer's cost of offering after-sales service \\
\hline$k_{R}$ & coefficient for retailer's cost of offering after-sales service \\
\hline$a_{0}$ & base market size for Segment 0 \\
\hline$a_{1}$ & base market size for Segment 1 \\
\hline$b_{0}$ & sensitivity for after-sales service for Segment 0 \\
\hline$b_{1}$ & sensitivity for after-sales service for Segment 1 \\
\hline$p$ & retail price $(p>w)$ \\
\hline$w$ & wholesale price $(w>c)$ \\
\hline$c$ & unit production cost $(c>0)$ \\
\hline$r$ & unit profit from an optional after-sales service $(r>0)$ \\
\hline$K$ & $K \equiv \frac{k_{R}}{2 b_{1}(P+r-w)}$ \\
\hline$S$ & $S \equiv \frac{\partial\left(\pi_{M}+\pi_{R}\right) / \partial \delta_{x}}{\partial\left(\pi_{M}+\pi_{R}\right) / \partial \delta_{y}}$ \\
\hline \multicolumn{2}{|l|}{ Superscripts } \\
\hline$*$ & Nash solutions for each case \\
\hline$m$ & Indicator of Case $m, m \in\{0,1,2,3,4,5\}$ \\
\hline
\end{tabular}


Table 2. Summary of the information structures.

\begin{tabular}{|c|c|c|c|}
\hline & $\begin{array}{l}\text { A manufacturer } \\
\text { knows }\end{array}$ & A retailer knows & Note \\
\hline Case 0 & both $\bar{x}$ and $\bar{y}$. & both $\bar{x}$ and $\bar{y}$. & $\begin{array}{l}\text { Certainty Case (by Kurata and Nam } \\
(2010) \text { ) }\end{array}$ \\
\hline Case 1 & neither $\bar{x}$ nor $\bar{y}$. & neither $\bar{x}$ nor $\bar{y}$. & Uncertainty Case (Base model) \\
\hline Case 2 & only $\bar{x}$. & only $\bar{x}$. & $\begin{array}{l}\text { Uncertainty Case with Unknown } \\
\text { Optional Service }\end{array}$ \\
\hline Case 3 & neither $\bar{x}$ nor $\bar{y}$. & both $\bar{x}$ and $\bar{y}$. & $\begin{array}{l}\text { Uncertainty Case with Knowledgeable } \\
\text { Retailer I }\end{array}$ \\
\hline Case 4 & only $\bar{x}$. & both $\bar{x}$ and $\bar{y}$. & $\begin{array}{l}\text { Uncertainty Case with Revised } \\
\text { Knowledgeable Retailer II }\end{array}$ \\
\hline Case 5 & only $\bar{x}$. & only $\bar{y}$. & Uncertainty Case with Mutuality \\
\hline
\end{tabular}


Table 3. Summary of the uncertainty effect under different information structures.

\begin{tabular}{|c|c|c|}
\hline & $\begin{array}{l}\text { Conditions for Ideal Type } 1 \\
\text { (each equilibrium solution } \\
\text { = each optimal solution) }\end{array}$ & $\begin{array}{l}\text { Conditions for Ideal Type } 2 \\
\quad \text { (sum of equilibrium solutions } \\
\quad \text { = sum of optimal solutions) }\end{array}$ \\
\hline $\begin{array}{c}\text { Case 0 } \\
\text { Certainty Model }\end{array}$ & Yes if and only if $b_{0}=0$ & None (Ideal Type 2 is impossible) \\
\hline $\begin{array}{c}\text { Case } 1 \\
\text { Base Model }\end{array}$ & $\begin{array}{c}\delta_{x}=-\frac{k_{R}}{2 b_{0}(p+r-w)}+\frac{k_{M}}{2 b_{0}(w-c)} \text { and } \\
\delta_{y}=\frac{\left(b_{0}+b_{1}\right) k_{R}}{2 b_{0} b_{1}(p+r-w)}-\frac{k_{M}}{2 b_{0}(w-c)}\end{array}$ & $\delta_{x}+\delta_{y}=\frac{k_{R}}{2 b_{1}(p+r-w)}$ \\
\hline $\begin{array}{l}\text { Case } 2 \\
\text { Unknown Optional } \\
\text { Service Model }\end{array}$ & $\begin{array}{c}\frac{k_{R}}{2 b_{0}(p+r-w)}-\frac{k_{M}}{2 b_{0}(w-c)}=0 \text { and } \\
\delta_{y}=\frac{\left(b_{0}+b_{1}\right) k_{R}}{2 b_{0} b_{1}(p+r-w)}-\frac{k_{M}}{2 b_{0}(w-c)}\end{array}$ & $\delta_{y}=\frac{k_{R}}{2 b_{1}(p+r-w)}$ \\
\hline $\begin{array}{c}\text { Case } 3 \\
\text { Knowledgeable Retailer } \\
\text { Model }\end{array}$ & None (Ideal Type 1 is impossible) & None (Ideal Type 2 is impossible) \\
\hline $\begin{array}{c}\text { Case } 4 \\
\text { Revised Knowledgeable } \\
\text { Retailer Model }\end{array}$ & None (Ideal Type 1 is impossible) & None (Ideal Type 2 is impossible) \\
\hline $\begin{array}{l}\text { Case } 5 \\
\text { Mutuality Model }\end{array}$ & $\begin{array}{c}\delta_{x}=\frac{k_{R}}{2 b_{1}(p+r-w)} \text { and } \\
\delta_{y}=\frac{k_{M}}{2 b_{1}(w-c)}\end{array}$ & $\delta_{x}=\frac{k_{R}}{2 b_{1}(p+r-w)}$ \\
\hline
\end{tabular}

